\title{
Poly(melamine-formaldehyde-silica) Composite Hydrogel for Methylene Blue Removal
}

\author{
Evânia Carvalho dos Santos ${ }^{a, b} *$ (D), Rafael Marinho Bandeira ${ }^{c}$ (D), Maria Leticia Vegad, \\ José Ribeiro dos Santos Juniorc (D) \\ aUniversidade Federal do Piauí, Programa de Pós-Graduação em Ciência e Engenharia dos Materiais, \\ Campus Ministro Petrônio Portella, CEP 64049-550, Teresina, PI, Brasil \\ ${ }^{b}$ Instituto Federal do Piaui, Campus Parnaiba, Avenida Monsenhor Antônio Sampaio, s/n. Bairro \\ Dirceu Arcoverde, CEP 64211-145, Parnaiba, PI, Brasil \\ 'Universidade Federal do Piauí, Departamento de Química, Campus Ministro Petrônio Portella, \\ CEP 64049-550, Teresina, PI, Brasil \\ ${ }^{d}$ Universidade Federal do Piauí, Departamento de Física, Campus Ministro Petrônio Portella, \\ CEP 64049-550, Teresina, PI, Brasil
}

Received: December 16, 2020; Revised: March 28, 2021; Accepted: May 11, 2021

In this work, we presented the synthesis and characterization of poly-melamine-formaldehyde-silica (PMF-Si) composite from poly-melamine-formaldehyde (PMF) and previously purified commercial sodium silicate used as a precursor of silica nanoparticles (Si-NPs). The materials were characterized by several physicochemical techniques such as XRD, FTIR, SEM, TEM, AFM, TGA, and DTG analysis to access their properties. We also studied hydrogel dehydration, rehydration, the potential of zero charge (PZC), and the adsorption capacity of the dye methylene blue (MB) in the hydrogel. From XRD analysis, PMF and PMF-Si materials presented amorphous profiles. AFM, SEM, and TEM images revealed a fibrous PMF structure and homogeneous dispersion of Si-NPs through the PMF-Si composite. The Si-NPs exhibited an average diameter between 10 to $15 \mathrm{~nm}$. The first PMF-Si hydration reached $93 \%$ after synthesis, and complete rehydration is possible up to $70 \%$ of dehydration. PMF-Si has the $\mathrm{PZC}$ at $\mathrm{pH}=1.22$ and, at superior values of $\mathrm{pH}$, the composite exhibits superior adsorption rates of MB. The adsorption tests performed to remove MB dye using PMF-Si hydrogel showed a $\mathrm{q}_{\max }$ of $140 \mathrm{mg} / \mathrm{g}$, which is superior to other materials routinely used for MB dye removal.

Keywords: Melamine-formaldehyde-silica, Hydrogel, Methylene blue, Dye removal.

\section{Introduction}

Hydrogels are composed of three-dimensional (3-D) insoluble polymer materials containing hydrophilic groups (modified or synthetic), capable of absorbing and retaining a considerable amount of water due to their morphological expansion $^{1-3}$. The increasing hydrogels synthesis methods aim to supply the demand for biocompatible materials and adequate for use in different applications such as pollutant removal, development of medicines, cosmetics, hygiene, and agricultural products ${ }^{2,3}$. Hydrogels are demanded because they present unique properties that account for biodegradability, biocompatibility, low-cost, facile synthesis, renewability, and excellent hydrophilicity ${ }^{4-7}$.

The use of polymers in the synthesis of hydrogels aims to increase hydrophilic capacity ${ }^{4}$ Poly(N-isopropyl acrylamide $)^{8}$, poly(ethylene glycol $)^{9}$, poly (vinyl alcohol $)^{10}$, poly(cellulose/chitosan $)^{11}$, and polyurethane ${ }^{12}$ are examples of polymers extensively used in hydrogel fabrication. These polymers have in common hydroxyl and nitrogen groups capable of establishing hydrogen or van der Waals bonds through their structures, enabling them to absorb significant amounts of water ${ }^{4}$.

*e-mail: evania@ifpi.edu.br
Poly-melamine-formaldehyde (PMF) polymer exhibits advantages that allow its use in hydrogels synthesis because of its large amounts of nitrogen, high resistance to chemical attack, and low-cost of production ${ }^{13}$. Besides, PMF offers a comprehensive 3-D structure that can be easily broken down; it can be applied in liquid filtration, sound, thermal and electrical insulation, development of components for construction industries, packages, high-quality laminated surfaces, fire retardant, heavy metal removal, dyes adsorption, etc $^{14-17}$. The methylol monomers exhibit attractive properties like low molar weight and up to 9 different possibilities of intermolecular interactions comprising 6 hydroxyl groups and 3 nitrogen atoms ${ }^{18}$. The numerous possible points of interaction make PMF suitable for hydrogel fabrication ${ }^{13}$.

Applications of PMF-based hydrogels are mentioned in recent studies ${ }^{19-22}$. Some of those works highlight new composites' development using synthetic or modified silica nanoparticles (Si-NPs) incorporated into $\mathrm{PMF}^{23-26}$. Si-NPs are indicated because of their high-active surface and high-density silanol groups ${ }^{27}$. Schwarz and Weber synthetized a xerogel by incorporation of Si-NPs into PMF aqueous solution ${ }^{28}$. They also synthesized a mesoporous polymelamineformaldehyde-silica (PMF-Si) composite through reverse emulsion polymerization ${ }^{13}$. 
The decision to incorporate Si-NPs into the PMF is due to beneficial properties, e.g., high surface area and available silanol groups, allowing PMF to cluster through intermolecular interactions, culminating in chemical and thermal stability, with applications like catalyzer, drugs, and adsorption of dyes ${ }^{27,29,30}$. Liu et al. ${ }^{31}$ reported the synthesis of a new material in which they used melamine-formaldehyde as a skeleton to stabilize the silica-monolith sorbent. Then, the authors found that the synthesized material has a high surface area and tunable surface properties. Liu et al. ${ }^{32}$ prepared mesoporous silvermelamine nanocomposites that presented a high adsorption capacity of $\mathrm{Hg}(\mathrm{II})$ as $589.99 \mathrm{mg} / \mathrm{g}$. Research like Liu and Li shows how promising composites' development is based on the melamine-formaldehyde polymer to obtain materials with better absorption properties, combined with low-cost and ease preparation.

Specifically, the generation of dye waste draws attention because it causes serious harm to humans; they behave as toxic and carcinogenic residues ${ }^{33-35}$ and present high stability to light, temperature, detergents, and microbial attack ${ }^{36}$. Several types of dyes are applied in textile, leather, paint, food, cosmetics, and paper industries ${ }^{37}$. Adsorption is a suitable method for metal ions and dye removal from the wastewater due to its low cost and simplicity compared to other procedures ${ }^{38-41}$. Heavy metals and dyes have been removed appropriately with the use of adsorbents obtained from chemical modification ${ }^{42-44}$. MB is a crucial azo dye commonly used in the industry ${ }^{37,45}$. However, MB dye causes severe damage to human health, including difficulty breathing, nausea, cyanosis, jaundice, quadriplegia, and tissue necrosis ${ }^{46}$.

Additionally, MB can impair photosynthetic processes in aquatic ecosystems ${ }^{45,47}$. Various chemical, physical and biological methods have been applied to remove dyes from wastewater, including chemical coagulation/ flocculation, ozonation, oxidation processes, ion exchange, and ultrafiltration ${ }^{48-51}$. However, they can have considerable disadvantages such as high cost and generation of secondary pollutants. Adsorption of dyes such as MB is a method that exhibits advantages over other methods in terms of efficiency, design, cost, and availability, especially when the dye concentration is not high ${ }^{52,53}$.

$\mathrm{MB}$ is commonly used for dyeing various types of materials, such as cotton, wool, and paper. MB's use causes dye residues in waters that need to be treated before being thrown into the environment. Therefore, there is an urgent need to develop non-toxic and inexpensive new materials to eliminate dye pollutants from water ${ }^{33}$. Adsorptive materials like PMF-Si are an eco-safety choice for wastewater dye removal $^{54}$. Therefore, among other applications for PMF-Si, the $\mathrm{MB}$ adsorption is of relevance in the present study.

Thus, using consolidated synthesis protocols through the sol-gel method of synthesis, the present work aims to synthesize a PMF-Si hydrogel via a low-cost procedure, using commercial sodium silicate solution as the precursor of Si-NPs. Furthermore, we used the synthesized hydrogel to remove methylene blue dye (MB). The main differential of this research is the formation of a composite (PMF-Si) in which Si-NPs are formed within the structural network of the PMF, simplifying the composite preparation process and eliminating the cost of acquiring commercial Si-NPs.

\section{Experimental}

\subsection{Sodium silicate purification}

Unpurified sodium silicate solution (also containing 22.66 wt. $\%$ of water, 9.2 wt.\% of sodium hydroxide, and 0.8 wt. $\%$ of iron) was purchased in a local city market in Teresina-PI, Brazil. We purified the sodium silicate material before using it in later stages. The previous purification procedure is recommended for impurity removal, such as iron ions. We used hydrochloric acid to solubilize iron precipitates forming their ions. The silica purification process consisted of using $200 \mathrm{~g}(120 \mathrm{~mL})$ of the commercial sodium silicate solution diluted to $1 \mathrm{~L}$ of deionized water at $25^{\circ} \mathrm{C}$. Then, $28 \mathrm{~mL}$ of concentrated hydrochloric acid (Vetec 32\%) was added dropwise while the solution was being stirred. The chemical Equation 1 describes the addition of hydrochloric acid to the diluted sodium silicate solution:

$$
\mathrm{Na}_{2} \mathrm{SiO}_{3}+2 \mathrm{HCl} \rightarrow \mathrm{SiO}_{2}+2 \mathrm{NaCl}+\mathrm{H}_{2} \mathrm{O}
$$

During the hydrochloric acid addition, there was precipitation of amorphous silica, and the $\mathrm{pH}$ value decreased to 8.0. The precipitate was filtered and washed with deionized water. The purified silica material was oven-dried at $65^{\circ} \mathrm{C}$ for $24 \mathrm{~h}$.

Finally, we added $135 \mathrm{~g}$ of the purified silica to the $4.5 \mathrm{~mol} / \mathrm{L} \mathrm{NaOH}$ (Vetec $97 \%$ ) solution under stirring at $70{ }^{\circ} \mathrm{C}$, forming $1 \mathrm{~L}$ of sodium silicate solution in the concentration of $274 \mathrm{~g} / \mathrm{mL}, \mathrm{pH}=14.0$. The conversion of silica to sodium silicate follows the chemical Equation 2:

$$
\mathrm{SiO}_{2}+2 \mathrm{NaOH} \rightarrow \mathrm{Na}_{2} \mathrm{SiO}_{3}+\mathrm{H}_{2} \mathrm{O}
$$

The purified sodium silicate solution was stoked for posterior use in the hydrogel formation to form Si-NPs.

\subsection{Melamine-formaldehyde polymer synthesis}

We have conducted the synthesis of PMF according to the work of Merline et al. ${ }^{55}$. The reaction between melamine and formaldehyde took place at a molar ratio of $1: 3$, and the polymerization mechanism of melamine-formaldehyde resin is known from the literature ${ }^{55}$. The initial procedure consisted of the dissolution of $1.5 \mathrm{~g}$ of melamine (SigmaAldrich 99\%) in $25 \mathrm{~mL}$ of deionized water $(18.2 \mathrm{M} \Omega . \mathrm{cm})$ in an open system. The solution was stirred and heated at $70{ }^{\circ} \mathrm{C}$, followed by the addition of $3 \mathrm{~mL}$ of formaldehyde (Merk 38\%), and kept under agitation to complete the PMF formation. The shift of white color to a translucid solution indicated that the reaction had happened. Later, we maintained the system with the exact condition of stirring and heating, and $30 \mathrm{~mL}$ of glycerin (Vetec $99.5 \%$ ) was added and stirred for another $10 \mathrm{~min}$. The glycerin consists of a source of hydroxyl groups to the system, which is susceptible to make hydrogen bonds allowing the formation of a structure capable of absorbing large amounts of water. Therefore, the final solution consists of the mixture of the PMF and glycerin used in the hydrogel synthesis.

\subsection{Hydrogel synthesis}

The silicate in acid medium forms hydrogels with Si-NPs and, depending on the proportion between siloxane ( $\mathrm{Si}-\mathrm{O}-\mathrm{Si}$ ) and silane $(\mathrm{Si}-\mathrm{OH})$ groups, and it can have more or less hydrophilic character ${ }^{56,57}$. The PMF provides the composite 
sustainment because it is a fibrous structure, one of the most important findings in this work. $280 \mathrm{~mL}$ of the previously prepared sodium silicate solution $(274 \mathrm{~g} / \mathrm{L})$ was added in a beaker with $670 \mathrm{~mL}$ of deionized water, as described in section 2.1. The diluted sodium silicate solution was heated to $70{ }^{\circ} \mathrm{C}$ and kept under stirring. Then, we added the previously prepared PMF-glycerin solution, as described in the previous section. After adding the PMF-glycerin solution, the mixture was stirred for $5 \mathrm{~min}$, followed by the dropwise addition of $10 \mathrm{~mL}$ of concentrated acetic acid (Vetec 99.5\%) to allow the formation of Si-NPs in the hydrogel. After the addition of acetic acid, we found the hydrogel $\mathrm{pH}=7.5$. Figure $1 \mathrm{a}$ represents the stages of formation of the PMF-glycerin resin, while Figure $1 \mathrm{~b}$ shows the formation of the PMF-Si composite. The original hydration of the PMF-Si composite was $93 \%$, determined after the preparation procedure.

\section{Melamine + formaldehyde}

(a)<smiles></smiles>

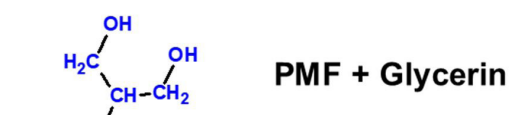<smiles>CC(C)ON1COCN(CO)c2nc(NCO)nc(n2)N(CO)COCN(c2nc(NCO)nc(NCO)n2)COCN1</smiles>

\section{Monomer Methylolmelamine}<smiles>OCNc1nc(NCO)nc(NCO)n1</smiles><smiles>COCCNc1nc(CO)nc(NCCO)n1</smiles><smiles>Nc1nc(NCOCN(COCNc2nc(NCO)nc(NCO)n2)c2nc(NCO)nc(NCO)n2)nc(N(CO)CO)n1</smiles>

(b)<smiles>C[Si](C)([O-])[O-]</smiles>

Sodium Silicate<smiles>OCNc1nc(NCO)nc(NOC(CO)CO)n1</smiles>

Figure 1. (a) Simplified depiction of PMF synthesis and incorporation of glycerin. (b) Preparation of the PMF-Si composite. 


\subsection{Material characterizations}

The synthesized hydrogel PMF-Si was submitted contact per time $48 \mathrm{~h}$ with sulfuric acid $(4.5 \mathrm{~mol} / \mathrm{L})$, nitric acid $(4 \mathrm{~mol} / \mathrm{L})$, phosphoric acid $(4 \mathrm{~mol} / \mathrm{L})$, methyl alcohol, ethyl alcohol, acetylene, and benzene solutions at $25^{\circ} \mathrm{C}$. However, the viscosity, the white color, solubility in water, the ability to not ignite, and the low water loss rate remained stable. We performed the physicochemical characterizations of the obtained materials by using several techniques: X-ray diffraction (XRD), Fourier transform infrared (FTIR), scanning electron microscopy (SEM), transmission electron microscopy (TEM), atomic force microscopy (AFM), thermogravimetric analysis (TGA); and humidity rate determination. We took the XRD measurements in a Bruker D8 Discover diffractometer and used a tube with a copper anode coupled to a Johansson monochromator for $\mathrm{K} \alpha_{1}$ operating at $40 \mathrm{kV}$ and $40 \mathrm{~mA}$ in the $2 \theta$ interval ranging from $5^{\circ}$ to $80^{\circ}$ for carrying out the analysis. The FTIR analyses of the materials were performed in $\mathrm{KBr}$ ( $3 \mathrm{wt} \%$ of the sample contents) in the region from $4000 \mathrm{~cm}^{-1}$ to $400 \mathrm{~cm}^{-1}$, with 16 scans and $4 \mathrm{~cm}^{-1}$ resolution, using a PerkinElmer equipment, model FTIR Spectrum 100. After the sample was fixed on a brass sample holder and covered with a thin gold film, we obtained SEM images to make the material's surface conductive. The images were acquired with a JEOL microscopy, model JSM-IT300, in high vacuum with the secondary electrons detector and electron acceleration voltage ranging from 5 to $15 \mathrm{kV}$. We carried out TEM analyzes in JEOL equipment, model JEM-2100, with a voltage of $200 \mathrm{kV}$. We dispersed the samples in hexane for $15 \mathrm{~min}$ and then subjected them to a low-frequency ultrasound bath. An aliquot of the obtained dispersion was dripped onto the copper grid covered with carbon and dried. We obtained AFM images with NTMDT AFM equipment in intermittent contact mode. Three different areas of the samples were analyzed. We performed TGA analysis using thermogravimetric equipment from TA Instruments, model SDT Q600 V20.9 Build 20, using an inert Argon atmosphere, with a $100 \mathrm{~mL} / \mathrm{min}$ flow rate, a heating ratio of $10^{\circ} \mathrm{C} / \mathrm{min}$, and temperature ranging from 10 to $1000^{\circ} \mathrm{C}$. The hydrogel's maximum hydration capacity and its rehydration performance were studied using a thermobalance Bel iThermo instrument, model $163 \mathrm{~L}$, with a fixed temperature at $65^{\circ} \mathrm{C}$ and room temperature at $24{ }^{\circ} \mathrm{C}$, respectively.

\subsection{Dehydration and rehydration of $P M F-S i$ hydrogel}

The tests of hydrogel dehydration and rehydration were determined using a digital thermobalance. The dehydration tests were carried out with the sample heating at $65{ }^{\circ} \mathrm{C}$ for $5 \mathrm{~h}$. The initial hydrogel weight (water + PMF-Si composite) used to calculate the dehydration percentage was $\sim 10 \mathrm{~g}$ in all tests. We performed the rehydration experiments from samples dehydrated from $10 \mathrm{~g}$ of hydrogel to lose 70, 75, 80, 85 , and $90 \%$ in mass at $65^{\circ} \mathrm{C}$. After reaching these mass-loss percentages, we hydrated the samples with the same mass of water lost. The system was then heated to remove the excess of water up to see just the hydrogel phase. We used the final mass of the heated system to calculate the percentage of rehydration. All experiments were performed in triplicate.

\section{6. $M B$ removal}

We evaluated the adsorption of MB (Vetec) on PMF-Si composite by batches containing $1 \mathrm{~g}$ of hydrogel $(72 \mathrm{mg}$ of dry PMF-Si) in contact with $10 \mathrm{~mL}(10-1500 \mathrm{mg} / \mathrm{L})$ of MB solution under stirring at $4000 \mathrm{rpm}$, for $10 \mathrm{~min}$, at $25^{\circ} \mathrm{C}^{58-60}$. We performed contact time, $\mathrm{pH}$ variation, and hydrogel reuse tests at the MB concentration of $50 \mathrm{mg} / \mathrm{L}$. The concentration $\mathrm{MB}$ was determined from the absorbance values at $664 \mathrm{~nm}$, using a Genesys UV-Vis spectrophotometer model 10S. We analyzed the solutions at different exposure times ranging from 5 to $120 \mathrm{~min}$ to elucidate MB's kinetic adsorption response on the hydrogel. The data was used to perform the adsorption isotherm where it was determined the adsorption capacity, $\mathrm{q}_{\mathrm{e}}(\mathrm{mg} / \mathrm{g})$, indicating the amount of adsorbed MB dye per amount of dry adsorbent using Equation 3:

$q_{e}=\frac{V\left(C_{o}-C_{e}\right)}{m}$

where $V$ is the solution volume (L), $C_{o}$ is the initial MB concentration $(\mathrm{mg} / \mathrm{L}), C_{e}$ is the equilibrium concentration $(\mathrm{mg} / \mathrm{L})$ of $\mathrm{MB}$, and $m$ the adsorbent mass $(\mathrm{g})$.

The potential of zero charge (PZC) of the composite PMF-Si was determined using the HORIBA SZ-100 equipment. Seven suspensions $(1 \% \mathrm{w} / \mathrm{v})$ were produced in $0.01 \mathrm{~mol} / \mathrm{L}$ $\mathrm{KCl}$ solution, varying the $\mathrm{pH}$ from 1-7. We used $\mathrm{HCl}$ and $\mathrm{NaOH}$ solutions to control the average $\mathrm{pH}$. The suspensions were stirred for $12 \mathrm{~h}$, maintained for another $12 \mathrm{~h}$ at $25^{\circ} \mathrm{C}$, and then PZC measurements were made with the supernatant. We evaluated the hydrogel's adsorption capacity for MB removal by varying the $\mathrm{pH}$ between 1 and 12 . The tests were performed with $1 \mathrm{~g}$ of the hydrogel hydrated, $10 \mathrm{~mL}$ of $\mathrm{MB}$ at a concentration of $50 \mathrm{mg} / \mathrm{L}$, and a temperature of $25{ }^{\circ} \mathrm{C}$. All experiences were done in triplicate.

\subsection{Evaluation of hydrogel reuse}

We performed the hydrogel reuse tests on MB dye adsorption using $1 \mathrm{~g}$ of hydrogel and $10 \mathrm{~mL}$ of $50 \mathrm{mg} / \mathrm{L} \mathrm{MB}$ solution at $25^{\circ} \mathrm{C}$ temperature. The dye's desorption was done by adding $7 \mathrm{~mL}$ of $1 \mathrm{~mol} / \mathrm{L} \mathrm{HCl}$ solution, and the contact time was $20 \mathrm{~min}$. After treatment with an acid solution, we performed 4 washing cycles with $12 \mathrm{~mL}$ of deionized water. Centrifugation of the solution at $4000 \mathrm{rpm}$ for $10 \mathrm{~min}$ was used to remove the acid and water. The MB concentration was determined from absorbance values at $664 \mathrm{~nm}$ using a Genesys UV-Vis model 10S spectrophotometer.

\section{Results and Discussion}

\subsection{Fourier transform infrared spectroscopy}

Figure 2 shows the FTIR spectra for melamine, PMF, and PMF-Si materials. The infrared spectrum of melamine is presented in Figure 2a, and the founded bands are similar to the one found by Ali et al. ${ }^{61}$. Bands at $3470 \mathrm{~cm}^{-1}$ and $3419 \mathrm{~cm}^{-1}$ are attributed to the asymmetric stretching of the $\mathrm{NH}_{2}$ group, and two large bands at $3333 \mathrm{~cm}^{-1}$ and $3132 \mathrm{~cm}^{-1}$ are attributed to the symmetric elongation and vibrational bending of primary amine ${ }^{16,55}$. The bands at 1655,1555 , 1469 , and $1439 \mathrm{~cm}^{-1}$ belong to the stretching of $\mathrm{C}=\mathrm{N}$ bonds 
present in the ring of 1,3,5triazine of melamine ${ }^{61,62}$. The band at $814 \mathrm{~cm}^{-1}$ is assigned to the vibrational bending of the ring in 1,3,5-triazine of melamine ${ }^{55,63}$. The band located at $1198 \mathrm{~cm}^{-1}$ is ascribed to the $\mathrm{C}-\mathrm{N}$ bond stretching at primary amine $^{62}$. PMF, Figure $2 b$, showed that the primary amine present in melamine has disappeared. The formation of broadband at $3336 \mathrm{~cm}^{-1}$ is attributed to hydroxyl groups' stretching vibration and demonstrates that melamine and formaldehyde are reticulated in the PMF resin ${ }^{16}$. The band around $2956 \mathrm{~cm}^{-1}$ is assigned to the stretch of primary carbon bonds, which is absent in neat melamine and occurs in PMF due to the reaction between melamine and formaldehyde ${ }^{64}$. We observed the methylene stretches $\left(\mathrm{CH}_{2}\right)$ at $1489 \mathrm{~cm}^{-165}$. The band located at $1155 \mathrm{~cm}^{-1}$ is ascribed to the lengthening of $\mathrm{CO}$ bonds ${ }^{65}$ and the band at $1061 \mathrm{~cm}^{-1}$ is attributed to an effect of the lengthening vibration of ether groups ${ }^{55}$. Bands localized at 1565,1489 , and $810 \mathrm{~cm}^{-1}$ are attributed to the melamine rings' vibration ${ }^{24}$. The band at $1330 \mathrm{~cm}^{-1}$ derives from the symmetrical stretch deformation of $\mathrm{CN}$ bonds ${ }^{66}$. Figure 2c shows the spectrum of the PMF-Si composite. The intense and wideband at $3340 \mathrm{~cm}^{-1}$ is due to the stretch vibration of $\mathrm{OH}$ of silanol groups in the PMF-Si composite structure, and possibly also due to the presence of residual water, being a consequence of its high hydrophilic character ${ }^{67}$.

Furthermore, the composite has free and encapsulated silanol groups due to the incorporation of Si-NPs into the PMF, Figure 1b. The band at $2943 \mathrm{~cm}^{-1}$ is assigned to the symmetrical stretch of the $\mathrm{CH}$ bond ${ }^{16,64}$. The band at 1565 $\mathrm{cm}^{-1}$ founded in the PMF is attributed to the vibration of melamine rings, and its displacement to $1571 \mathrm{~cm}^{-1}$ in the PMF-Si spectrum reveals an interaction between silanol groups, from silica, and rings of melamine structure ${ }^{24}$. The band at $1050 \mathrm{~cm}^{-1}$ results from the $\mathrm{C}-\mathrm{O}$ stretch of glycol, demonstrating $\mathrm{OH}$ groups' presence stemming from glycerin ${ }^{68}$. The band at $924 \mathrm{~cm}^{-1}$ corresponds to the asymmetric stretching of Si-OH groups. The bands at 1111 and $786 \mathrm{~cm}^{-1}$ indicate symmetrical extension, while the band at $471 \mathrm{~cm}^{-1}$ indicates asymmetrical stretching of $\mathrm{Si}-\mathrm{O}-\mathrm{Si}$ and $\mathrm{O}-\mathrm{Si}-\mathrm{O}$ groups, respectively. Those groups are present in silica belonging to the PMF-Si composite. Those groups account for hydrophilic property, which contributes to water retention by the hydrogel, demonstrating the successful formation of the PMF-Si composite ${ }^{69-72}$.

\subsection{XRD of melamine, $\mathrm{SiO}_{2}, \mathrm{PMF}$, and $\mathrm{PMF}-\mathrm{Si}$ composite}

Figure 3 shows diffractograms acquired for melamine, $\mathrm{SiO}_{2}, \mathrm{PMF}$, and PMF-Si composite in the $2 \theta$ interval ranging from 6 to $80^{\circ}$. Melamine displayed a well-defined crystalline profile with peaks between $15^{\circ}$ and $45^{\circ}$. The founded peaks at $17.4,20.6,25.3,30.6,31.6,33.6,34.8$, and $44.9^{\circ}$ follow the literature, corresponding to the melamine crystallographic profile $^{73}$. In opposition, PMF displayed an amorphous structure, indicating no crystalline contribution from melamine in the polymer structure. PMF showed a typical prominent peak located at $13.1^{\circ}$ and $27.4^{\circ}$, indicating that melamine reacted with formaldehyde to form methylol monomers and, consequently, the growth of the PMF structure happened ${ }^{16}$.

The purified silica material exhibited a typical amorphous structure with a distinguished peak centered at 22.6 $6^{074,75}$. PMFSi composite also exhibited an amorphous profile and did not show the central peak at $27.4^{\circ}$, as it happened with PMF. Then, the PMF-Si composite structure is dependent on the amorphous silica addition. PMF-Si composite showed two new peaks centered at $9.3^{\circ}$ and $22.2^{\circ}$ because of interactions between PMF and Si-NPs. The peak centered at $9.3^{\circ}$ must be attributed to the displacement of the peak assigned to the PMF centered at $13.1^{\circ}$. We believe that the same situation may have occurred with the peak centered at $22.2^{\circ}$ attributed to the PMF-Si composite, contributing from peaks related to silica and PMF, located at $22.6^{\circ}$ and $27.4^{\circ}$, respectively. Note that a significant change in the PMF morphology occurs when Si-NPs are embedded in its structure. This change is responsible for increasing the water absorption capacity in the PMF-Si composite.

\subsection{Microscopy analysis}

We performed a microscopy examination to acquire SEM, TEM, and AFM images to get an insight into the morphological structure of the synthesized materials. Figure 4 exhibits SEM images of neat melamine, silica, PMF, and

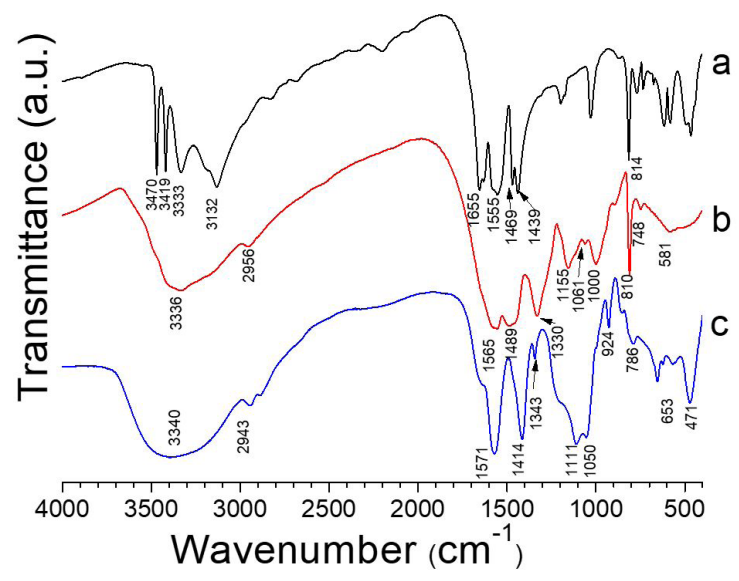

Figure 2. FTIR spectra of (a) melamine, (b) PMF, and (c) PMF-Si composite.

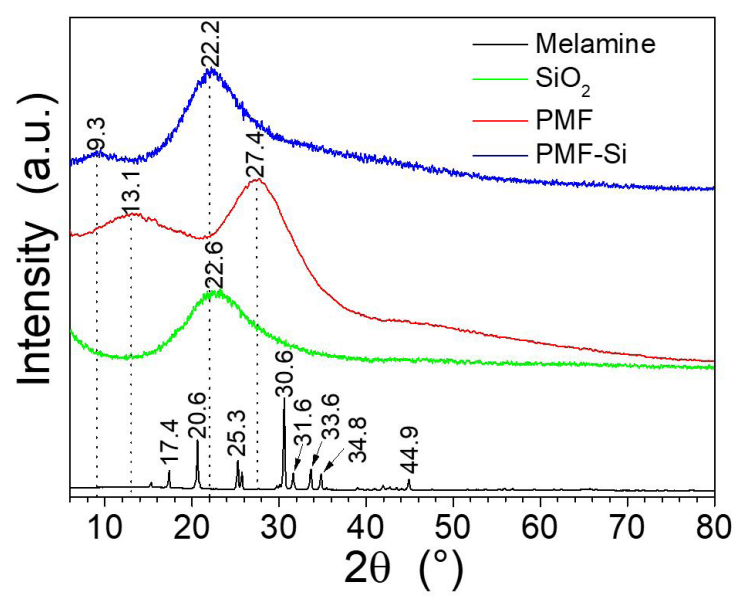

Figure 3. XRD of melamine, $\mathrm{SiO}_{2}, \mathrm{PMF}$, and PMF-Si composite. 

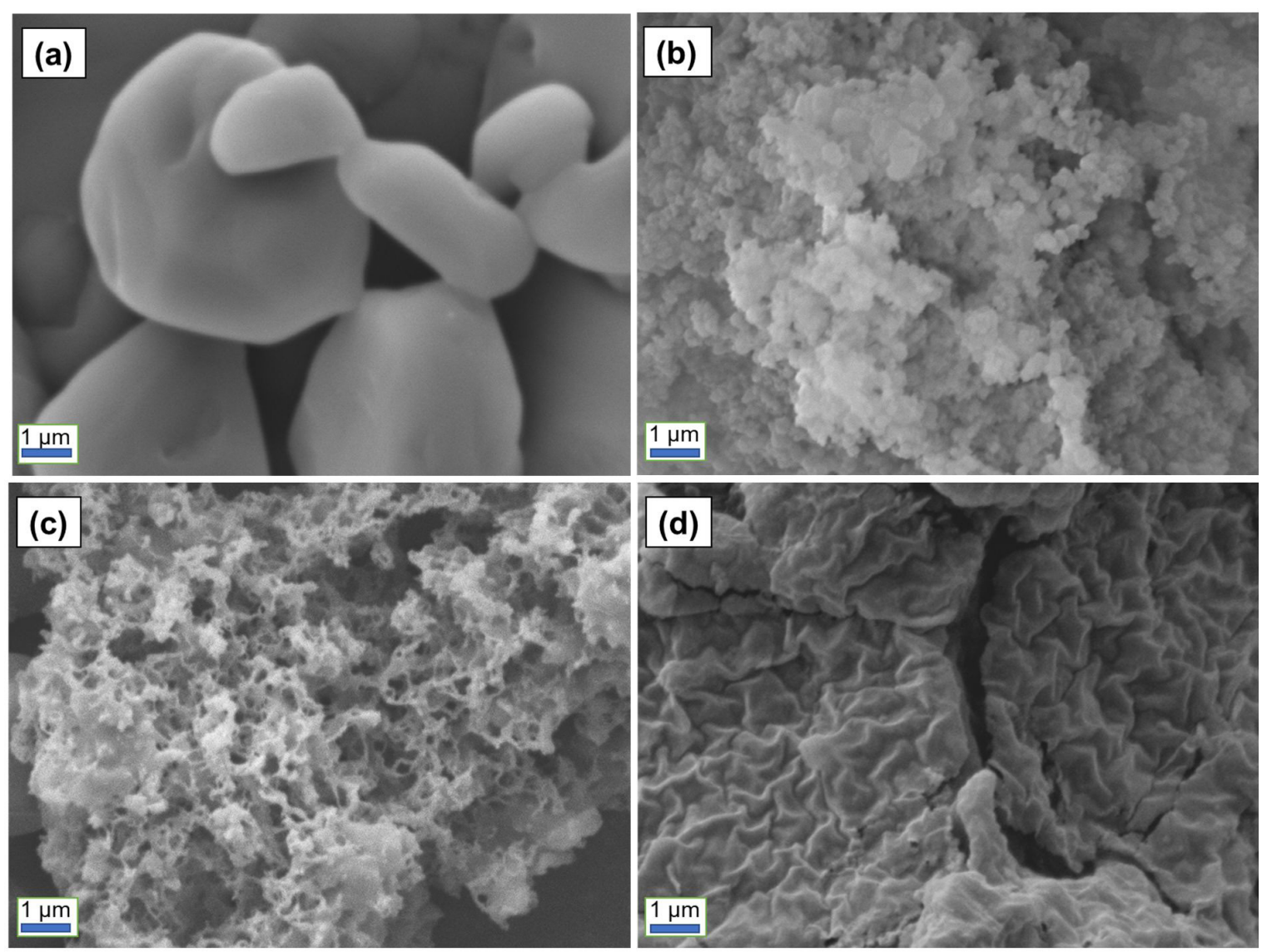

Figure 4. SEM images of (a) melamine, (b) purified silica obtained from sodium silicate neutralized with acetic acid, (c) PMF, and (d) dry PMF-Si composite.

dry PMF-Si composite. Figure 4a shows the melamine morphology consisting of white-color crystalline agglomerates in solid-state at $25^{\circ} \mathrm{C}^{63,76}$. Figure $4 \mathrm{~b}$ shows the purified silica precipitates presenting a cauliflower-like morphological appearance, representing an amorphous material, and agrees with the XRD spectrum shown in Figure 3. The amorphous silica profile was also verified in other studies ${ }^{76,77}$.

Figure $4 \mathrm{c}$ shows the PMF morphology with a sponge-like porous structure. This arrangement is like the PMF images obtained by Schwarz and Weber ${ }^{28}$. In opposition, Figure 4d demonstrates that the dry PMF-Si composite presents a distinct structure compared to its precursors and resembling dehydrated human skin.

We obtained TEM images for silica and dry PMF-Si composite, Figure 5. Figure 5a shows the silica microparticles with a diameter of about $\sim 0.45 \mu \mathrm{m}$. The silica microparticles are interconnected and forming an elongated agglomerate due to its high active surface and elevated density of silanol groups, which is typical of amorphous silica material in agreement with the results already examined ${ }^{27}$. Figure $5 b$ displays the Si-NPs homogeneously distributed within the PMF matrix. The presence of no agglomerated and welldistributed Si-NPs within the PMF-Si composite contributes to achieving better stability and water absorption capability by the hydrogel. From Figure 5b, we determined the Si-NPs diameter using the software ImageJ. These Si-NPs exhibited an average diameter between 10 to $15 \mathrm{~nm}$, as shown in Figure 6. The used precursor concentration of the Si-NPs avoided particle agglomeration, being a positive result for the PMF-Si composite ${ }^{28}$.

Figures $5 \mathrm{c}$ and d display the PMF-Si composite morphology. In the lower-left part of Figure 5c, fibers are spaced in the dry composite where large amounts of water can be confined by hydration. In the central region of the same image, fibers are close to each other, featuring an area where a large amount of water was removed from the composite. Figure $5 \mathrm{~d}$ shows another region in which the PMF-Si composite has a circular geometry, and the fibrous structure is spread out in a 3D network that resembles a sponge structure. In the hydrogel dehydrating process, the PMF-Si composite shows a dense aspect of fibers. Cross-link bonds also characterize PMF. When re-hydrated, the polymer chains pull away, serving as structural support to achieve maximum water absorption. The supplied TEM images demonstrated that the PMF-Si composite consists of fibers and Si-NPs responsible for improved water absorption capacity.

We obtained AFM images of the PMF to better observe the polymer fibers' morphological aspect, Figure 7. We prepared PMF film by adding $5 \mathrm{~mL}$ of the PMF solution on a Petri dish to obtain the images. The sample was heated at 

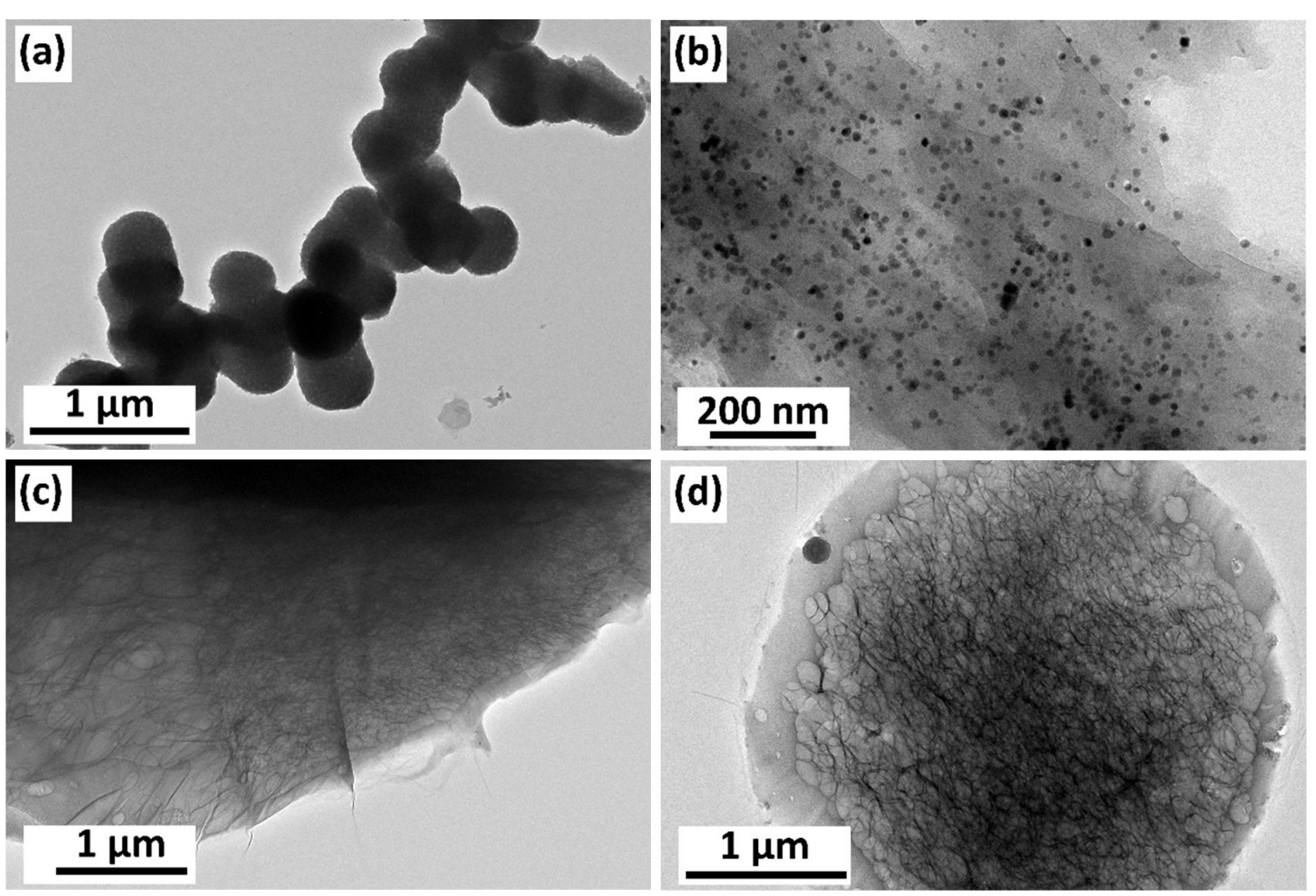

Figure 5. TEM images of (a) amorphous silica produced through sodium silicate neutralized with acetic acid and (b-d) dry PMF-Si composite.

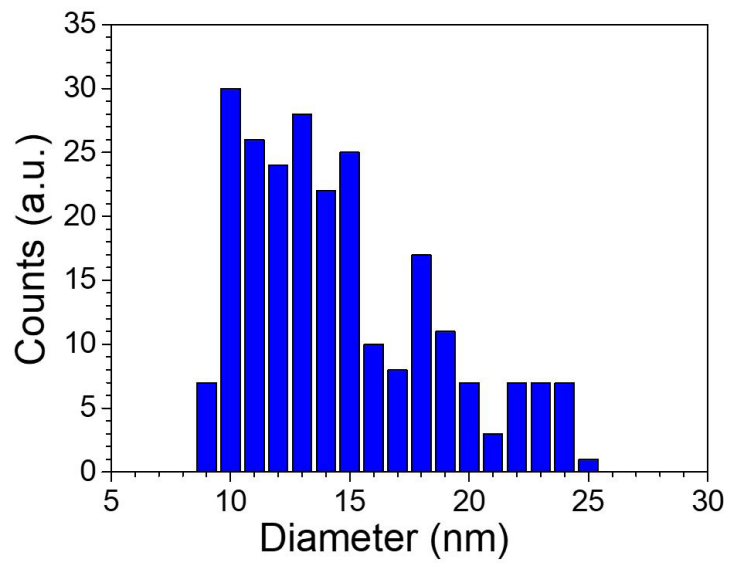

Figure 6. Si-NPs diameter distribution over the PMF-Si composite.

$60{ }^{\circ} \mathrm{C}$ in an oven for $24 \mathrm{~h}$ to form the polymer film. Then, the film was removed from the plate, cut, and submitted to AFM analysis. The images were acquired in different areas of the film. In these images, we can see the disposal of the fibers in vertical disposal. The fibers are spread all over the film and present an average diameter between 1 and $0.5 \mu \mathrm{m}$.

Figure 7a shows dendrimers' formation in the fibers' terminal positions, which suggest possible separation and forming of new thinner fibers after water absorption forming the hydrogel. The polymer film also shows the fibers juxtaposed, different from what happens when the fibers are inside the hydrogel. In the hydrogel, the polymer fibers are separated to maximize water absorption. The AFM images confirm that the PMF constitutes fibers that promote structural reinforcement to the hydrogel, allowing its stability. Liao et al. ${ }^{10}$ also observed the fibrous structure of PMF. Figure $7 \mathrm{c}$ is an interfacial approximation between PMF fibers and reveals a phase's presence, apparently, distant from the fibers, occurring at their edges. We believe that is because the fibers become thicker, characterized as a PMF residue that could make the fiber thicker if the polymerization process were continued. It was not possible to perform the AFM images of the PMF-Si composite. The operational impediment is due to the high hydrophilic nature that does not allow the composite fixation for analysis.

\subsection{Thermogravimetric analysis}

Figure 8 exhibits the TG and DTG curves of melamine, PMF, $\mathrm{SiO}_{2}$, and PMF-Si composite. Table 1 summarizes the main events from the thermogravimetric results for the materials mentioned above. Figure 8a shows the melamine thermogravimetric profile with a unique event situated between 220 to $356{ }^{\circ} \mathrm{C}$, without any residue remaining, consistent with the literature ${ }^{78}$, which corresponds to the melamine decomposition. TG and DTG curves of PMF, Figure 8b, exhibited three events related to its thermal properties. The first event occurred between 29 and $325^{\circ} \mathrm{C}$ associated with polymer dehydration and decomposition of small precursor molecules of PMF synthesis.

The second event occurred between 362 and $416{ }^{\circ} \mathrm{C}$, demonstrating that the PMF suffered decomposition of less-dense morphological structures such as the residue of 
PMF embedded on the surface of the fibers and major of the fibers that presented small diameter, which was previously discussed in Figure 7c. The third event occurred between 420 and $935^{\circ} \mathrm{C}$, attributed to the decomposition of the most compacted PMF structure and thicker fibers. The $10 \%$ of residual mass from the PMF decomposition is composed of carbon ashes ${ }^{64}$. The TG and DTG curves of silica, Figure 8c, revealed two relevant events, partly superimposed. The first event located between 48 and $115^{\circ} \mathrm{C}$ is attributed to the silica dehydration, followed by a second event related to
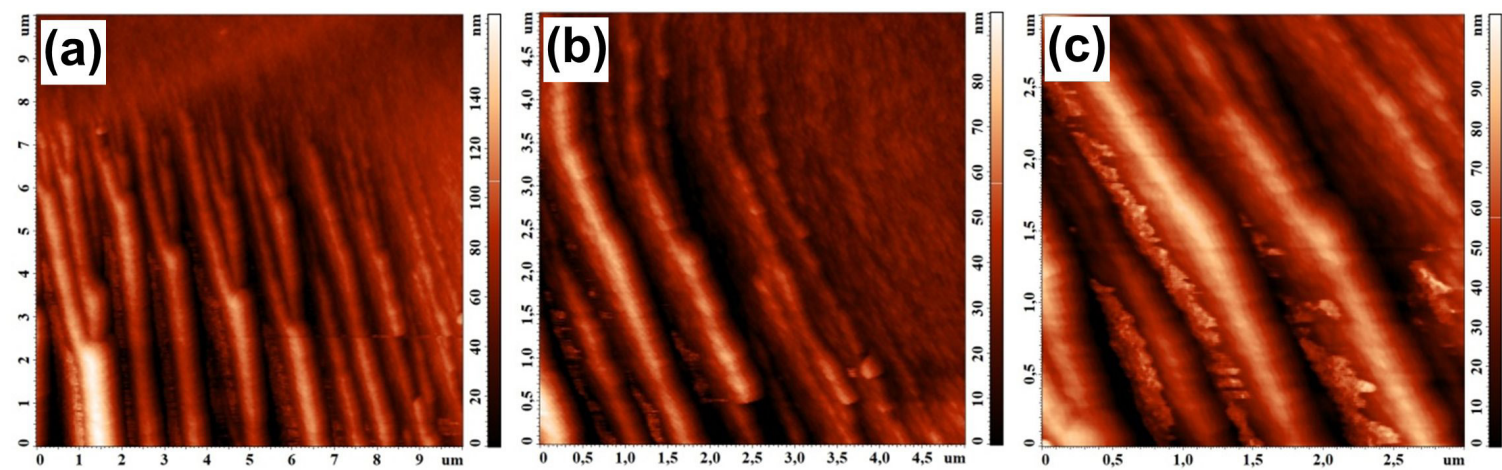

Figure 7. AFM images of PMF film surface at (a) $100 \mu \mathrm{m}^{2}$, (b) $25 \mu \mathrm{m}^{2}$, and (c) $9 \mu \mathrm{m}^{2}$.

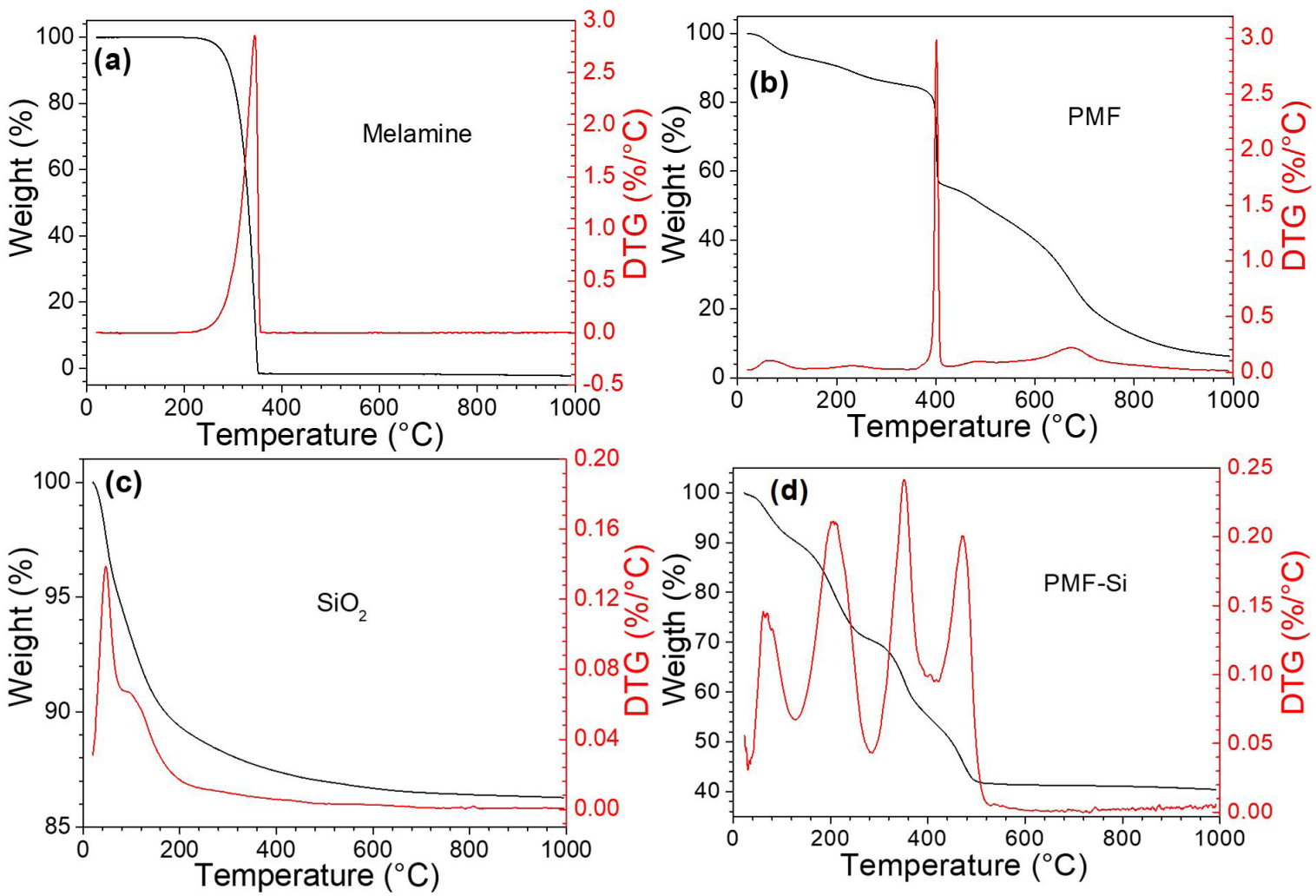

Figure 8. TG and DTG of (a) melamine, (b) PMF, (c) $\mathrm{SiO}_{2}$, and (d) PMF-Si composite.

Table 1. Summary of the events related to the thermal properties of melamine, PMF, $\mathrm{SiO}_{2}$, and PMF-Si composite samples. The weight $(\%)$ and the residue from the thermal decomposition of the materials are indicated.

\begin{tabular}{lccccccccc}
\hline \multicolumn{1}{c}{ Sample } & ${ }^{\circ} \mathrm{C}$ & $\mathrm{wt} \%$ & ${ }^{\circ} \mathrm{C}$ & $\mathrm{wt} \%$ & ${ }^{\circ} \mathrm{C}$ & $\mathrm{wt} \%$ & ${ }^{\circ} \mathrm{C}$ & $\begin{array}{c}\text { Residue } \\
(\%)\end{array}$ \\
\hline Melamine & $220-356$ & 100 & & & & & & - \\
\hline PMF & $29-325$ & 14 & $362-416$ & 28 & $420-935$ & 48 & & 10 \\
\hline SiO & $48-115$ & 8 & $115-660$ & 5 & & & & 87 \\
\hline PMF-Si & $43-126$ & 10 & $126-282$ & 20 & $282-418$ & 17 & $418-525$ & 11 & 42 \\
\hline
\end{tabular}


the thermal decomposition of residual organic compounds, e.g., acetic acid, used in the silica synthesis, which extends to $\sim 660{ }^{\circ} \mathrm{C}$. It is possible to verify a high residual content ( $\sim 87 \%$ ) characterizing silica content free of water and organic matter. Figure $8 \mathrm{~d}$ presents the TG and DTG curves of the dry hydrogel containing PMF-Si composite. The curve reveals the occurrence of four relevant events associated with composite dehydration and its thermal decomposition. The first one is attributed to the dehydration process located between 43 to $126^{\circ} \mathrm{C}$ with a mass-loss percentile of $\sim 10 \%$. Although the hydrogel was previously dehydrated at $60{ }^{\circ} \mathrm{C}$ for $24 \mathrm{~h}$, its highly hygroscopic nature allowed water absorption, even using a dehumidified storage protocol. The second event between 126 and $282{ }^{\circ} \mathrm{C}$ had a mass-loss percentile of $20 \%$ and corresponds to the organic compounds from silica synthesis. The third event occurred between 282 and $418^{\circ} \mathrm{C}$, attributed to the glycerin evaporation, which has a boiling point of 290 ${ }^{\circ} \mathrm{C}$ and presented a mass-loss percentile of about $\sim 17 \%$. The fourth and last event occurred between 418 and $525{ }^{\circ} \mathrm{C}$, attributed to the PMF fibers' thermal decomposition, which presented a mass-loss percentile of $\sim 11 \%$. The residue from the PMF-Si composite decomposition is due to the Si-NPs and the carbonized organic matter corresponding to $\sim 42 \%$.

From the results revealed here, it is possible to conclude that the PMF-Si composite presents a compatible thermal behavior with its composition, showing a series of thermal events associated with the dehydrated hydrogel's content. TG and DTG analyzes indicate that the PMF-Si composite is less stable than the PMF. That is because the fibers in the PMF-Si composite allowed a better material dispersion and, possibly, due to the segregation of thick fibers into thinner fibers while the composite is hydrated. Besides, the presence of Si-NPs favored the dispersion of the PMF fibers benefiting hydrogel stability.

\subsection{Dehydration and rehydration results}

The dehydration tests showed substantial water loss in the first two hours of heating at $65{ }^{\circ} \mathrm{C}$ representing a decrease in water content of approximately $80 \%$, as shown in Figure 9a. The hydrogel dehydration reached $\sim 0.728 \mathrm{~g}$ after $4 \mathrm{~h}$ of heating and remained constant for an extra $1 \mathrm{~h}$.
The rehydration performance seriously affects the hydrogel's properties, a critical issue in its practical applications ${ }^{79}$. From Figure $9 \mathrm{~b}$, the hydrogel achieves complete rehydration even after reaching $70 \%$ of dehydration. Hydrogel dehydration below $70 \%$ also showed complete rehydration. We found that weight loss of up to $70 \%$ characterizes the hydrogel's reversibility returning to its original water contents. When we increased the hydrogel dehydration to $90 \%$, its rehydration capacity considerably decreases, such that when dehydrating the hydrogel by $90 \%$, rehydration is about $\sim 30 \%$. The success in hydrogel rehydration (maximum dehydration is up to $70 \%$ ) is due to its excellent hydrophilic properties. Rehydration is possible because the silanol groups $(2 \equiv \mathrm{Si}-\mathrm{OH} \rightarrow \equiv$ $\mathrm{Si}-\mathrm{O}-\mathrm{Si} \equiv+\mathrm{H}_{2} \mathrm{O}$ ) and hydroxyl groups (Figure 1) are present on the PMF-Si composite surface and between its mesopores structure (Figure 4c), allowing the hydrogel to recover most of the original volume of water through the return effect ${ }^{80}$. The practical consequence of the facile hydrogel rehydration is attributed to the stabler Si-NPs adsorbed on the PMF structure.

\subsection{Potential of zero charge and methylene blue removal}

The Potential of zero charge (PZC) of the composite occurred at $\mathrm{pH}=1.22$, as shown in Figure 10a. At $\mathrm{MB}$ solution and $\mathrm{pH}$ below the $\mathrm{PZC}$, the composite surface is positively charged, and at $\mathrm{pH}$ higher than the $\mathrm{PZC}$, the composite surface is negatively charged ${ }^{81}$. Therefore, there is a reduced $\mathrm{MB}$ adsorption capacity when the $\mathrm{pH}$ is lower than $\mathrm{PZC}$, and this is due to the composite having a positive potential on its surface when the $\mathrm{pH}$ is lower than 1.22 (see Figure $10 \mathrm{~b}$ ). However, when the $\mathrm{pH}$ is higher than 1.22 , the PMF-Si composite surface becomes negative and electrostatic attraction occurs easier with the cationic MB dye molecules. The adsorption by hydrogen interaction justifies that even at lower $\mathrm{pH}$ than PZC, the PMF-Si shows an adsorption process.

$\mathrm{MB}$ adsorption mechanism on $\mathrm{Si}-\mathrm{NPs}$ is by electrostatic forces and hydrogen interactions on the silane groups ${ }^{82,83}$ since MB is positively charged and has amine groups ${ }^{81,84}$. Figure 11 shows a scheme of how adsorption of MB on silane groups can occur. The model shows the interfacial
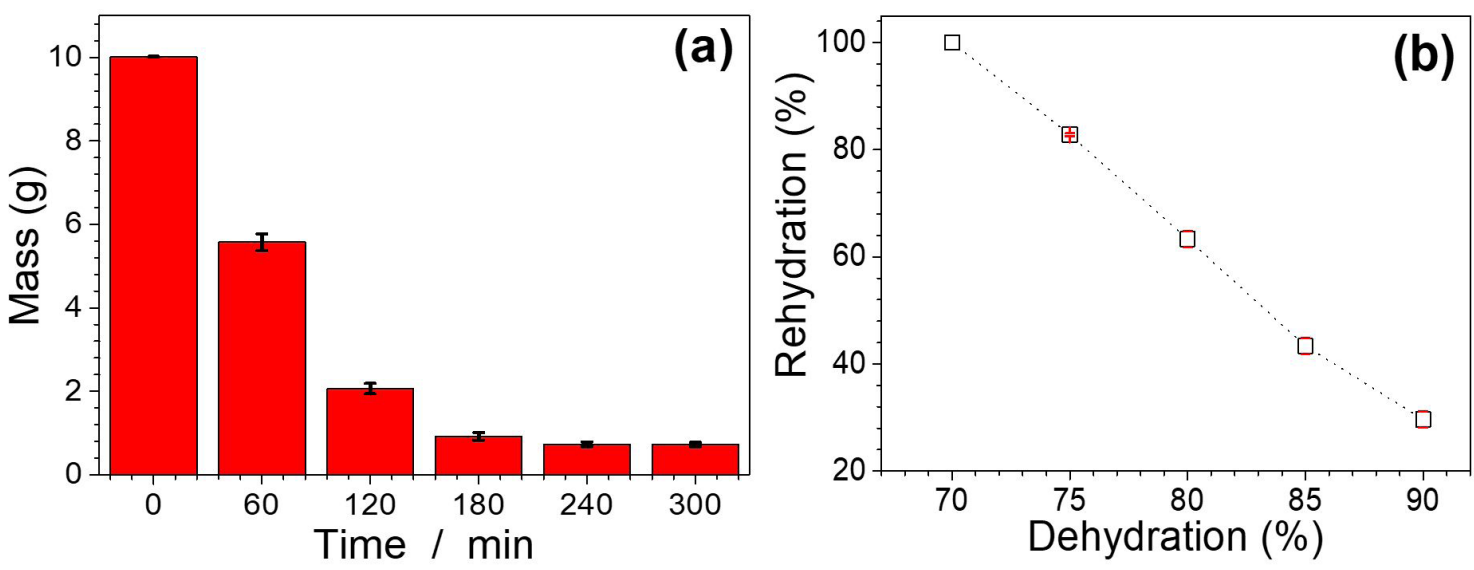

Figure 9. (a) Time evolution of the hydrogel dehydration at $65^{\circ} \mathrm{C}$, and (b) rehydration percentual after dehydration achieve $70,75,80$, 85 , and $90 \%$ of water loss. 

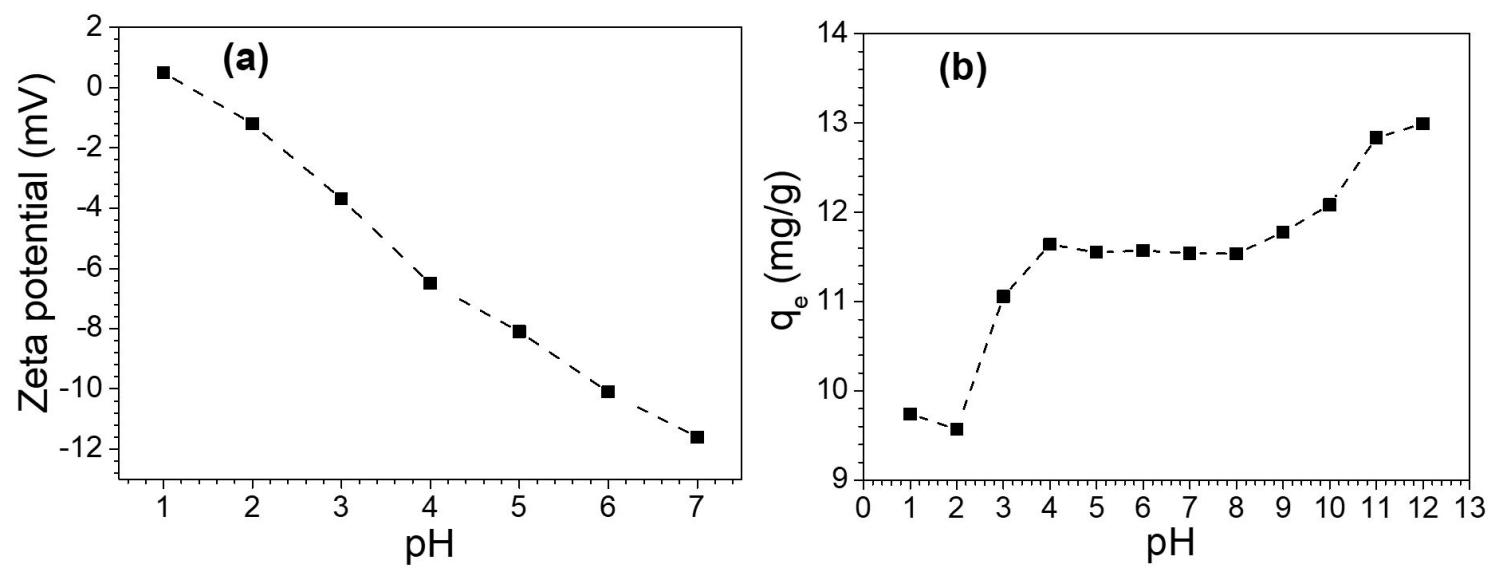

Figure 10. a) Zeta potential of PMF-Si and b) Evolution of the adsorption capacity of MB dye on PMF-Si at different $\mathrm{pH}$ values.

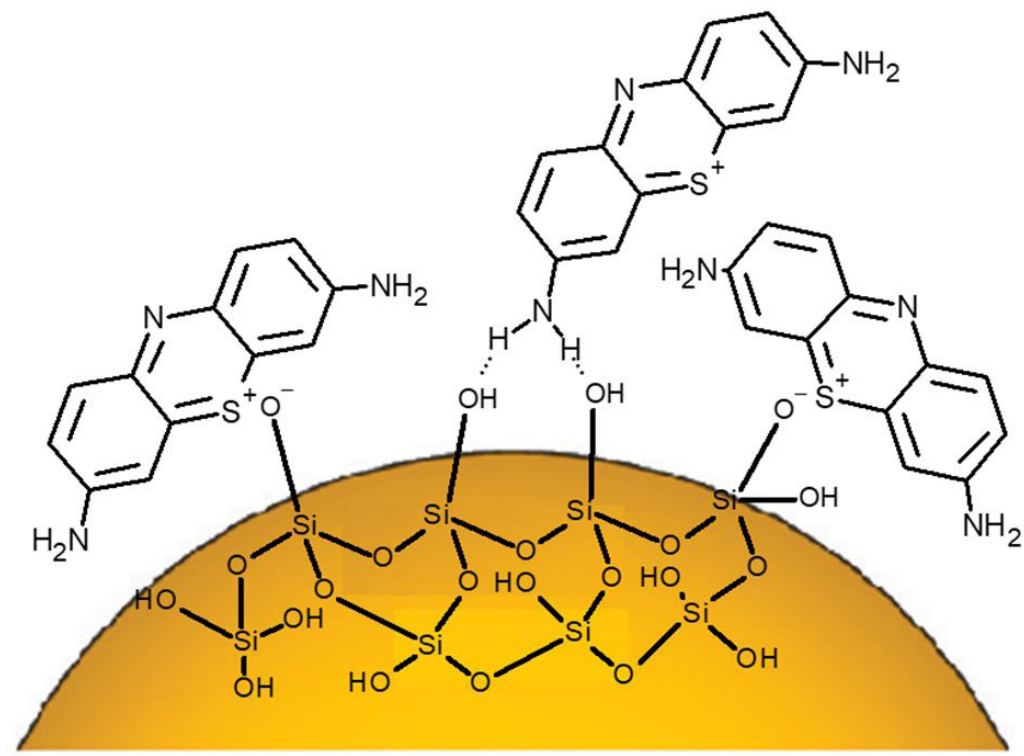

Figure 11. Proposed mechanism of MB adsorption by PMF-Si composite.

interaction arising from the silanolate groups' interactions (Si-O-) derived from silicate, and silane groups, with $\mathrm{MB}$ dye because of hydrogen interactions.

The adsorption of methylene blue dye is affected by $\mathrm{pH}$ variation ${ }^{85}$. The MB in aqueous solutions is presented in the form of positively charged ions (cationic dye), and its adsorption degree is influenced by the surface charge of the adsorbent, which has its value modified according to the $\mathrm{pH}$ variation of the medium ${ }^{86}$. The $\mathrm{pH}$ can cause functional groups' desorption on the adsorbent's active sites and changes in the surface charge of the adsorbent ${ }^{87}$. The adsorption capacity of MB on PMF-Si increased at $\mathrm{pH}$ higher than 2, agreeing with $\mathrm{PZC}$, Figure 10a, and reached stability in the $\mathrm{pH}$ range between 4-9. At a $\mathrm{pH}$ higher than 9 , there is an increase in the adsorption capacity of $\mathrm{MB}^{88}$.

The calibration curve from the samples containing different MB dye concentrations in the hydrogel was acquired, Figure 12a. A linear correlation between the absorbance of the samples and the residual dye concentration in the hydrogel is represented by the equation $\mathrm{y}=0.1844 \mathrm{x}+0.0078$, with an $\mathrm{R}^{2}=0.99946$. The accurate adjustment allowed us to calculate the final MB dye concentration of a different solution using the equation mentioned above. Figure $12 \mathrm{~b}$ shows the contact time between the MB dye and PMF-Si hydrogel and displays the associated dye removal percentage. The curve indicates the maximum MB dye removal percentage reached $96 \%$ with a short contact time of $5 \mathrm{~min}$. Figure $12 \mathrm{~b}$ also suggests a rapid interaction between the MB dye and the hydrogel. Although the percentage of dye removal continues to increase with the contact time, its increase is not significant, although it allows for additional removal with a contact time of $90 \mathrm{~min}$. Therefore, we achieved a short adsorption time of the dye removal by PMF-Si, which is a relevant result. The high dye removal percentage with a short adsorption time makes MB dye removal by PMF-Si hydrogel a versatile method for practical applications.

Langmuir model was used to fit the absorption data analysis of MB dye in hydrogel samples. This model comprises a 
defined number of active sites and the occurrence of monolayer adsorption on a homogeneous surface ${ }^{89,90}$. The isothermal curve showed in Figure 13 follows the Langmuir adsorption model. The curve's shape indicates no competition between the solvent and the adsorbate, which means the PMF-Si hydrogel is a potential adsorbent of MB dye.

We calculated the adsorption capacity using Equation 4:

$q_{e}=\frac{q_{\max } K_{L} C_{e}}{1+K_{L} C_{e}}$

where $q_{\max }$ represents the theoretical maximum adsorption capacity in $\mathrm{mg} / \mathrm{g}, C_{e}$ is the concentration at the equilibrium in $\mathrm{mg} / \mathrm{L}$, and is the Langmuir's constant in $\mathrm{L} / \mathrm{mg}^{91}$. The adsorption curve (Figure 13) reveals that the hydrogel has a maximum MB dye adsorption capacity of around $140 \mathrm{mg} / \mathrm{g}$ and a Langmuir's constant of about $3.16 \times 10^{3} \mathrm{~L} / \mathrm{mg}$. The calculated MB dye adsorption capacity value is higher than the ones reported for other materials such as rice hulls $(\sim 40 \mathrm{mg} / \mathrm{g})^{92}$, clay $(\sim 72 \mathrm{mg} / \mathrm{g})^{93}$, waste activated carbon $(\sim 15 \mathrm{mg} / \mathrm{g})^{81}$, MCM-41/chondroitin sulfate hybrid hydrogels $(\sim 123 \mathrm{mg} / \mathrm{g})^{94}$, polyvinyl alcohol/acrylic acid/poly4styrene sulphonic acid hydrogel $(\sim 131 \mathrm{mg} / \mathrm{g})^{95}$. The PMF-Si hydrogel synthesized by Schwarz and Weber used commercial Si-NPs and exhibited an MB dye adsorption capacity of $\sim 812 \mathrm{mg} / \mathrm{g}^{13}$. In our study, Si-NPs were formed in the hydrogel synthesis process, while Schwarz and Weber used commercial Si-NPs. The hydroxylated surface of the PMF-Si composite provided by silanol groups accounted for the strong interaction between the hydrogel and MB dye molecules. Therefore, PMF-Si hydrogel for MB dye removal should be encouraged since it is an effective and inexpensive strategy.

\subsection{Evaluation of the reuse of hydrogel for $M B$ adsorption}

Figure 14 displays the adsorption capacity of the hydrogel after successive reuse cycles. The process of removing MB from the PMF-Si hydrogel's surface, in its reuse, occurs by adding $1 \mathrm{~mol} / \mathrm{L} \mathrm{HCl}$ solution, followed by washes with deionized water until $\mathrm{pH}=6$ is reached. The strategy of lowering the $\mathrm{pH}$ to remove $\mathrm{MB}$ from the composite surface is because, at $\mathrm{pH}$ values below the $\mathrm{PZC}$, there is desorption of many dye molecules. The adsorption capacity of PMF-Si gradually decreased from $92 \%$ to $42 \%$ after 7 adsorption cycles. The washing process justifies the decrease in adsorption capacity with the $\mathrm{HCl}$ solution. The low $\mathrm{pH}$ promotes a reduction in the silica surface's negative charge density,
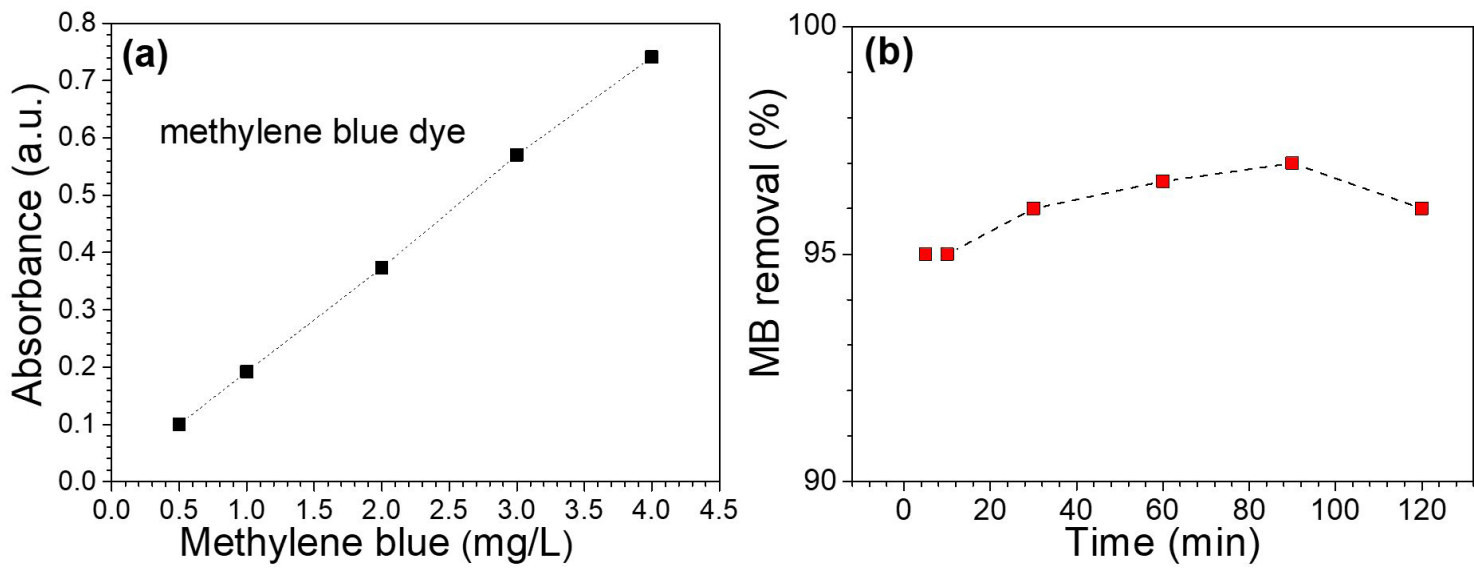

Figure 12. (a) MB dye absorption calibration curve and (b) contact time of MB dye (concentration 10 g/L) with PMF-Si hydrogel.

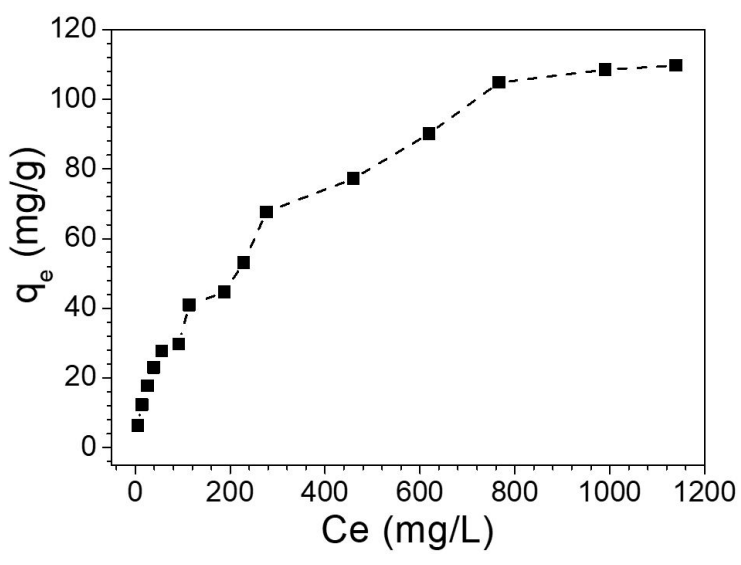

Figure 13. Isothermal adsorption curve of the MB dye in the PMF-Si hydrogel follows the Langmuir adsorption model.

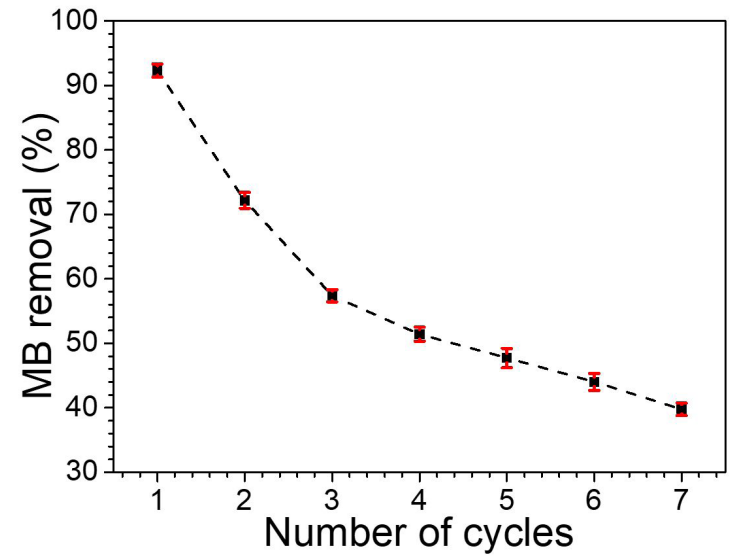

Figure 14. Evaluation of the reuse of hydrogel in the adsorption process of MB dye. 
making the material less $\mathrm{MB}$ adsorbent ${ }^{88}$. Another factor to consider is the loss of Si-NPs during successive washing cycles. Therefore, the indication of PMF-Si hydrogel's use for $\mathrm{MB}$ removal is a viable alternative since the materials have a low-cost, and the synthesis is simplified.

\section{Conclusions}

We successfully synthesized PMF-Si composite to form a hydrogel with promising properties for several applications (dye adsorbent, agriculture, fire-retardant, etc.). Thermal analysis implied that the PMF-Si composite presents a stable structure with well-defined stages of decomposition. The Si-NPs were obtained from purified sodium silicate and exhibited similar properties to the commercial Si-NPs, making this study an alternative for preparing quality and low-cost Si-NPs for hydrogel fabrication. The synthesized PMF-Si composite displayed fibrous structure provided by PMF, responsible for the hydrogel structural support. The Si-NPs showed a diameter between 10 and $15 \mathrm{~nm}$ helped to improve the water absorption capacity. The intrinsic PMF-Si composite hydration reached a maximum of $93 \mathrm{wt} \%$ of water. Complete rehydration is only possible when the maximum mass loss of water reaches $70 \mathrm{wt} \%$. The composite showed $\mathrm{PZC}$ at $\mathrm{pH}=1.22$, which means that its structure at $\mathrm{pH}$ higher than 1.22 is negatively charged, and electrostatic forces occur with the cationic MB dye molecules. The MB dye adsorption capacity, $\mathrm{q}_{\max }=140 \mathrm{mg} / \mathrm{g}$, was higher than other materials routinely used for MB dye removal, demonstrating that the PMF-Si hydrogel can be used to remove MB dye and possibly other dyes. Although the adsorption capacity of PMF-Si gradually decreased from $92 \%$ to $42 \%$ after 7 adsorption cycles, the composite is low-cost, which makes viable its use for MB adsorption proposal.

\section{Acknowledgments}

This study was financed in parts by the Coordenação de Aperfeiçoamento de Pessoal de Nível Superior -Brasil (CAPES) -Finance Code 001.

\section{References}

1. Aouada FA, Moura MR, Orts WJ, Mattoso LHC. Preparation and characterization of novel micro- and nanocomposite hydrogels containing cellulosic fibrils. J Agric Food Chem. 2011;59(17):9433-42. http://dx.doi.org/10.1021/jf202347h.

2. Estroff LA, Hamilton AD. Water gelation by small organic molecules. Chem Rev. 2004;104(3):1201-18. http://dx.doi. org $/ 10.1021 /$ cr0302049.

3. Yu Z, Bai B, Wang H, Ran X, Jin G, Sun J, et al. Morphology-tuning by changing the composition of a binary hydrogel comprising thymidine and melamine. Mater Sci Eng C. 2011;31(5):880-4. http://dx.doi.org/10.1016/j.msec.2011.02.007.

4. Nascimento DWS, Moura MR, Mattoso LHC, Aouada FA. Hybrid biodegradable hydrogels obtained from nanoclay and carboxymethylcellulose polysaccharide: Hydrophilic, kinetic, spectroscopic and morphological properties. J Nanosci Nanotechnol. 2017;17(1):821-7. http://dx.doi.org/10.1166/ jnn.2017.12664.

5. Güler MA, Gök MK, Figen AK, Özgümüş S. Swelling, mechanical and mucoadhesion properties of Mt/starch-g-PMAA nanocomposite hydrogels. Appl Clay Sci. 2015;112-113:44-52. http://dx.doi.org/10.1016/j.clay.2015.04.019.
6. Haraguchi K, Takada T. Characteristic sliding frictional behavior on the surface of nanocomposite hydrogels consisting of organic-inorganic network structure. Macromol Chem Phys. 2005;206(15):1530-40. http://dx.doi.org/10.1002/macp.200500105.

7. Zohuriaan-Mehr MJ, Omidian H, Doroudiani S, Kabiri K. Advances in non-hygienic applications of superabsorbent hydrogel materials. J Mater Sci. 2010;45(21):5711-35. http:// dx.doi.org/10.1007/s10853-010-4780-1.

8. Barbosa DHO, Moura MR, Aouada A. Hidrogéis nanocompósitos de polissacarídeo com zeólita: avaliação do processo da asorção do pesticida paraquat. Quim Nova. 2018;41(4):380-5.

9. Gauvin R, Parenteau-Bareil R, Dokmeci MR, Merryman WD, Khademhosseini A. Hydrogels and microtechnologies for engineering the cellular microenvironment. Wiley Interdiscip Rev Nanomed Nanobiotechnol. 2012;4(3):235-46. http://dx.doi. org/10.1002/wnan.171.

10. Liao H, Liu Y, Wang Q, Duan W. Preparation and properties of a poly(vinyl alcohol) hydrogel-melamine formaldehyde foam composite. Polym Compos. 2019;40(5):2067.

11. Li M, Wang Z, Li B. Adsorption behaviour of congo red by cellulose/chitosan hydrogel beads regenerated from ionic liquid. Desalination Water Treat. 2016;57(36):16970-80.

12. Hu J. Controlled release of hydrogel modified textile products. J Control Release. 2011;152:e31-3. http://dx.doi.org/10.1016/j. jconrel.2011.08.104.

13. Schwarz D, Weber J. Synthesis of mesoporous poly(melamineformaldehyde) particles by inverse emulsion polymerization. J Colloid Interface Sci. 2017;498:335-42. http://dx.doi. org/10.1016/j.jcis.2017.03.064.

14. Zhang Y, Duan H, Wang X, Meng X, Qin D. Preparation and properties of composites based on melamine-formaldehyde foam and nano-Fe 3 O 4. J Appl Polym Sci. 2013;130(4):2688-97. http://dx.doi.org/10.1002/app.39514.

15. Kohlmayr M, Stultschnik J, Teischinger A, Kandelbauer A. Drying and curing behaviour of melamine formaldehyde resin impregnated papers. J Appl Polym Sci. 2014;131(3):1-9. http:// dx.doi.org/10.1002/app.39860.

16. Banu HT, Meenakshi S. Synthesis of a novel quaternized form of melamine-formaldehyde resin for the removal of nitrate from water. J Water Process Eng. 2017;16:81-9. http://dx.doi. org/10.1016/j.jwpe.2016.12.003.

17. Chen J, Jiang M, Han J, Liu K, Liu M, Wu Q. Syntheses of magnetic GO@melamine formaldehyde resin for dyes adsorption. Mater Res Express. 2019;6(8):086103. http://dx.doi. org/10.1088/2053-1591/ab1ba6.

18. Edwards GA, Trafford MA, Hamilton AE, Buxton AM, Bardeaux MC, Chalker JM. Melamine and melamine-formaldehyde polymers as ligands for palladium and application to SuzukiMiyaura cross-coupling reactions in sustainable solvents. J Org Chem. 2014;79(5):2094-104. http://dx.doi.org/10.1021/ jo402799t.

19. Bao R, Tan B, Liang S, Zhang N, Wang W, Liu W. A $\pi-\pi$ conjugation-containing soft and conductive injectable polymer hydrogel highly efficiently rebuilds cardiac function after myocardial infarction. Biomaterials. 2017;122:63-71. http:// dx.doi.org/10.1016/j.biomaterials.2017.01.012.

20. Rezazadeh H, Moghadam PN, Ehsanimehr S, Fareghi AR. Synthesis of a new magnetic nanocomposite hydrogel based on poly(vinyl acetate-co-maleic anhydride)/melamine for efficient dye removal. J Elastomers Plast. 2020;52(1):70-89. http://dx.doi.org/10.1177/0095244318824380.

21. He YR, Li XL, Li XL, Tan ZY, Zhang D, Chen HB. Aerogel based on melamine-formaldehyde and alginate: simply removing of uranium from aqueous solutions. J Mol Liq. 2019;289:111154. http://dx.doi.org/10.1016/j.molliq.2019.111154.

22. Hu W, Wang Z, Xu Y, Wang X, Xiao Y, Zhang S, et al. Remodeling of inherent antimicrobial nanofiber dressings with melamine- 
modified fibroin into neoskin. J Mater Chem B Mater Biol Med. 2019;7(21):3412-23. http://dx.doi.org/10.1039/C9TB00276F.

23. Bal A, Aca I, Güçlü G. A novel type nanocomposite coating basead on alkyd-malamine formaldehyde resin containing modified silica: preparation and film properties. J Appl Polym Sci. 2011;125:E85-92.

24. Mou S, Lu Y, Jiang Y. A facile and cheap coating method to prepare $\mathrm{SiO}_{2}$ /melamine-formaldehyde and $\mathrm{SiO}_{2}$ /urea-formaldehyde composite microspheres. Appl Surf Sci. 2016;384:258-62. http://dx.doi.org/10.1016/j.apsusc.2016.04.156.

25. Pevida C, Drage TC, Snape CE. Silica-templated melamineformaldehyde resin derived adsorbents for $\mathrm{CO} 2$ capture. Carbon N Y. 2008;46(11):1464-74. http://dx.doi.org/10.1016/j. carbon.2008.06.026.

26. Xiong Z, Chen N, Wang Q. Preparation and properties of melamine formaldehyde resin modified by functionalized nano- $\mathrm{SiO}_{2}$ and polyvinyl alcohol. Polym Polymer Compos. 2021;29(2):96-106. http://dx.doi.org/10.1177/0967391120903548.

27. Chen L, Guo X, Jia Z, Tang Y, Wu L, Luo Y, et al. High reactive sulphide chemically supported on silica surface to prepare functional nanoparticle. Appl Surf Sci. 2018;442:673-81. http:// dx.doi.org/10.1016/j.apsusc.2017.12.265.

28. Schwarz D, Weber J. Waterborne colloidal polymer/silica hybrid dispersions and their assembly into mesoporous poly(melamineformaldehyde) xerogels. Langmuir. 2015;31(30):8436-45. http:// dx.doi.org/10.1021/acs.langmuir.5b00990.

29. Slowing II, Vivero-escoto JL, Wu C, Lin VS. Mesoporous silica nanoparticles as controlled release drug delivery and gene transfection carriers. Adv Drug Deliv Rev. 2008;60(11):127888. http://dx.doi.org/10.1016/j.addr.2008.03.012.

30. Choi E, Lim D, Kim S. Hydrolytic surface erosion of mesoporous silica nanoparticles for efficient intracellular delivery of cytochrome c. J Colloid Interface Sci. 2020;560:416-25. http:// dx.doi.org/10.1016/j.jcis.2019.10.100.

31. Liu Z, Jiang P, Huang G, Yan X, Li XF. Silica Monolith Nested in Sponge (SiMNS): a composite monolith as a new solid phase extraction material for environmental analysis. Anal Chem. 2019;91(5):3659-66. http://dx.doi.org/10.1021/acs. analchem.8b05707.

32. Liu H, Li S, Feng L, Hua Y, Cai Y, Yin M, et al. A selective colorimetric and efficient removal strategy for mercury (II) using mesoporous silver-melamine nanocomposites synthesized by controlled supramolecular self-assembly. J Hazard Mater. 2020;388:121798. http://dx.doi.org/10.1016/j.jhazmat.2019.121798.

33. Ait Himi M, El Ghachtouli S, Amarray A, Zaroual Z, Bonnaillie P, Azzi M. Removal of azo dye Calcon using polyaniline films electrodeposited on $\mathrm{SnO}_{2}$ substrate. Phys Chem Res. 2020;8(1):111-24.

34. Eftekhari S, Habibi-Yangjeh A, Sohrabnezhad SH. Application of AlMCM-41 for competitive adsorption of methylene blue and rhodamine B: thermodynamic and kinetic studies. J Hazard Mater. 2010;178(1-3):349-55. http://dx.doi.org/10.1016/j. jhazmat.2010.01.086.

35. Efimov MN, Vasilev AA, Muratov DG, Baranchikov AE, Karpacheva GP. IR radiation assisted preparation of $\mathrm{KOH}$-activated polymer-derived carbon for methylene blue adsorption. J Environ Chem Eng. 2019;7(6):103514. http://dx.doi.org/10.1016/j. jece.2019.103514.

36. He S, Fang H, Xu X. Filtering absorption and visual detection of methylene blue by nitrated cellulose acetate membrane. Korean J Chem Eng. 2016;33(4):1472-9. http://dx.doi.org/10.1007/ s11814-015-0231-7.

37. Varjani S, Rakholiya P, Ng HY, You S, Teixeira JA. Microbial degradation of dyes: an overview. Bioresour Technol. 2020;314:123728.

38. Pandey S, Tiwari S. Facile approach to synthesize chitosan based composite - Characterization and cadmium(II) ion adsorption studies. Carbohydr Polym. 2015;134:646-56. http://dx.doi. org/10.1016/j.carbpol.2015.08.027.

39. Pandey S. A comprehensive review on recent developments in bentonite-based materials used as adsorbents for wastewater treatment. J Mol Liq. 2017;241:1091-113. http://dx.doi. org/10.1016/j.molliq.2017.06.115. [Internet]

40. Pandey S, Ramontja J. Natural bentonite clay and its composites for dye removal: current state and future potential [Internet]. Am J Chem Appl. 2016;3(2):8-19 [cited 2020 Dec 16]. Available from: http://www.openscienceonline.com/journal/ajca

41. Pandey S, Do JY, Kim J, Kang M. Fast and highly efficient removal of dye from aqueous solution using natural locust bean gum based hydrogels as adsorbent. Int J Biol Macromol. 2020;143:60-75. http://dx.doi.org/10.1016/j.ijbiomac.2019.12.002.

42. Pandey S, Fosso-Kankeu E, Spiro MJ, Waanders F, Kumar N, Ray SS, et al. Equilibrium, kinetic, and thermodynamic studies of lead ion adsorption from mine wastewater onto MoS2 clinoptilolite composite. Mater Today Chem. 2020;18:100376. http://dx.doi.org/10.1016/j.mtchem.2020.100376.

43. Pandey S, Ramontja J. Guar gum-grafted poly(acrylonitrile)templated silica xerogel: nanoengineered material for lead ion removal. J Anal Sci Technol. 2016;7(1):24. http://dx.doi. org/10.1186/s40543-016-0103-8.

44. Makhado E, Pandey S, Modibane KD, Kang M, Hato MJ. Sequestration of methylene blue dye using sodium alginate poly(acrylic acid)@ZnO hydrogel nanocomposite: kinetic, isotherm, and thermodynamic investigations. Int J Biol Macromol. 2020;162:60-73. http://dx.doi.org/10.1016/j. ijbiomac.2020.06.143.

45. Alver E, Metin AÜ, Brouers F. Methylene blue adsorption on magnetic alginate/rice husk bio-composite. Int J Biol Macromol. 2020;154:104-13. http://dx.doi.org/10.1016/j. ijbiomac.2020.02.330.

46. Paulino AT, Guilherme MR, Reis AV, Campese GM, Muniz EC, Nozaki J. Removal of methylene blue dye from an aqueous media using superabsorbent hydrogel supported on modified polysaccharide. J Colloid Interface Sci. 2006;301(1):55-62. http://dx.doi.org/10.1016/j.jcis.2006.04.036.

47. Zhang P, Lo I, O'Connor D, Pehkonen S, Cheng H, Hou D. High efficiency removal of methylene blue using SDS surfacemodified $\mathrm{ZnFe}_{2} \mathrm{O}_{4}$ nanoparticles. J Colloid Interface Sci. 2017;508:39-48. http://dx.doi.org/10.1016/j.jcis.2017.08.025.

48. Ma J, Huang D, Zou J, Li L, Kong Y, Komarneni S. Adsorption of methylene blue and Orange II pollutants on activated carbon prepared from banana peel. J Porous Mater. 2015;22(2):301-11. http://dx.doi.org/10.1007/s10934-014-9896-2.

49. Sohrabnezhad S, Pourahmad A. Comparison absorption of new methylene blue dye in zeolite and nanocrystal zeolite. Desalination. 2010;256(1-3):84-9. http://dx.doi.org/10.1016/j. desal.2010.02.009.

50. Wang B, Gao B, Wan Y. Comparative study of calcium alginate, ball-milled biochar, and their composites on aqueous methylene blue adsorption. Environ Sci Pollut Res Int. 2019;26(12):1153541. http://dx.doi.org/10.1007/s11356-018-1497-1.

51. Li B, Guo J, Lv K, Fan J. Adsorption of methylene blue and $\mathrm{Cd}(\mathrm{II})$ onto maleylated modified hydrochar from water. Environ Pollut. 2019;254:113014.

52. Yao Y, Xu F, Chen M, Xu Z, Zhu Z. Adsorption behavior of methylene blue on carbon nanotubes. Bioresour Technol. 2010;101(9):3040-6. http://dx.doi.org/10.1016/j.biortech.2009.12.042.

53. Üner O. Hydrogen storage capacity and methylene blue adsorption performance of activated carbon produced from Arundo donax. Mater Chem Phys. 2019;237:121858.

54. Kausar A, Iqbal M, Javed A, Aftab K, Nazli Z-H, Bhatti $\mathrm{HN}$, et al. Dyes adsorption using clay and modified clay: a review. J Mol Liq. 2018;256:395-407. http://dx.doi.org/10.1016/j. molliq.2018.02.034. 
55. Merline DJ, Vukusic S, Abdala AA. Melamine formaldehyde: curing studies and reaction mechanism. Polym J. 2013;45(4):4139. http://dx.doi.org/10.1038/pj.2012.162.

56. Khedkar MV, Somvanshi SB, Humbe AV, Jadhav KM. Surface modified sodium silicate based superhydrophobic silica aerogels prepared via ambient pressure drying process. J Non-Cryst Solids. 2019;511:140-6. http://dx.doi.org/10.1016/j. jnoncrysol.2019.02.004

57. Du Z, Guo L, Zheng T, Cai Q, Yang X. Formation of core-shell structured calcium silicate fiber via sol-gel electrospinning and controlled calcination. Ceram Int. 2019;45(18):23975-83. http:// dx.doi.org/10.1016/j.ceramint.2019.08.099.

58. Liu S, Chen X, Ai W, Wei C. Anew method to prepare mesoporous silica from coal gasification fine slag and its application in methylene blue adsorption. J Clean Prod. 2019;212:1062-71. http://dx.doi.org/10.1016/j.jclepro.2018.12.060

59. Novais RM, Ascensão G, Tobaldi DM, Seabra MP, Labrincha JA. Biomass fly ash geopolymer monoliths for effective methylene blue removal from wastewaters. J Clean Prod. 2018;171:78394. http://dx.doi.org/10.1016/j.jclepro.2017.10.078.

60. Hor KY, Chee JMC, Chong MN, Jin B, Saint C, Poh PE, et al. Evaluation of physicochemical methods in enhancing the adsorption performance of natural zeolite as low-cost adsorbent of methylene blue dye from wastewater. J Clean Prod. 2016;118:197-209. http://dx.doi.org/10.1016/j.jclepro.2016.01.056

61. Ali IH, Mohammed YI, Himdan TA. Melamine-attapalgite and attapalgite- melamine- formaldehyde physical interactions : synthesis and characterzation. Al-Mustansiriyah J Sci. 2013;24(1):105-14.

62. Wang Y, Xie Y, Zhang Y, Tang S, Guo C, Wu J, et al. Anionic and cationic dyes adsorption on porous poly-melamine-formaldehyde polymer. Chem Eng Res Des. 2016;114:258-67. http://dx.doi. org/10.1016/j.cherd.2016.08.027

63. Ming G, Duan H, Meng X, Sun G, Sun W, Liu Y, et al. A novel fabrication of monodisperse melamine-formaldehyde resin microspheres to adsorb lead (II). Chem Eng J. 2016;288:74557. http://dx.doi.org/10.1016/j.cej.2015.12.007.

64. Bal A, Acar I, Güçlü G. Thermal oxidative degradation kinetics of nanocomposite alkyd-melamine formaldehyde resin containing modified silica. Instrum Sci Technol. 2014;42(3):345-56. http:// dx.doi.org/10.1080/10739149.2013.867504.

65. Chen LF, Shen Q, Shen JP, Shi DT, Chen T, Yu HR. Studies and comparison of the liquid adsorption and surface properties of $\alpha$-, $\beta$ - and $\gamma$-cyclodextrins by FTIR and capillary rise method. Colloids SurfA Physicochem Eng Asp. 2012;411:69-73. http:// dx.doi.org/10.1016/j.colsurfa.2012.07.003.

66. Silva LS, Ferreira FJL, Silva MS, Citó AMGL, Meneguin AB, Sábio RM, et al. Potential of amino-functionalized cellulose as an alternative sorbent intended to remove anionic dyes from aqueous solutions. Int J Biol Macromol. 2018;116:1282-95. http://dx.doi.org/10.1016/j.ijbiomac.2018.05.034.

67. Ahmed MJK, Ahmaruzzaman M, Bordoloi MH. Novel Averrhoa carambola extract stabilized magnetite nanoparticles: a green synthesis route for the removal of chlorazol black e from wastewater. RSC Advances. 2015;5(91):74645-55. http://dx.doi. org/10.1039/C5RA13970H.

68. Borin A, Poppi RJ. Application of mid infrared spectroscopy and iPLS for the quantification of contaminants in lubricating oil. Vib Spectrosc. 2005;37(1):27-32. http://dx.doi.org/10.1016/j. vibspec.2004.05.003.

69. Mokrini A, Siu A, Robitaille L, Gonzalez L, Sanchez F. Investigation of advanced hybrid PEM based on sulfonyl fluoride PFSA and grafted inorganic nanoparticles. ECS Trans. 2010;33(1 Part 1):823-38. http://dx.doi.org/10.1149/1.3484576.

70. Cui S, Cheng W, Shen X, Fan M, Russell AT, Wu Z, et al. Mesoporous amine-modified $\mathrm{SiO} 2$ aerogel: a potential $\mathrm{CO} 2$ sorbent. Energy Environ Sci. 2011;4(6):2070-4. http://dx.doi. org/10.1039/c0ee00442a.
71. Prado AGS, Faria EA, Padilha PM. Aplicação e modificação química da sílica gel obtida de areia. Quim Nova. 2005;28(3):5447.

72. Duraia EM, Mansurov ZA, Tokmolden S, Beall GW. Preparation of highly aligned silicon oxide nanowires with stable intensive photoluminescence. Phys B Condens Matter. 2010;405(4):117680. http://dx.doi.org/10.1016/j.physb.2009.11.031.

73. Zhang Y, Pan Q, Chai G, Liang M, Dong G, Zhang Q, et al. Synthesis and luminescence mechanism of multicolor-emitting g-C3N4 nanopowders by low temperature thermal condensation of melamine. Sci Rep. 2013;3(1):1-8. http://dx.doi.org/10.1038/ srep01943.

74. Musić S, Filipović-Vinceković N, Sekovanić L. Precipitation of amorphous $\mathrm{SiO}_{2}$ particles and their properties. Brazilian $\mathrm{J}$ Chem Enfineering. 2011;28(1):89-94. http://dx.doi.org/10.1590/ S0104-66322011000100011

75. Yu LY, Huang ZX, Shi MX. Synthesis and characterization of silica by sol-gel method. Adv Mat Res. 2014;1030-1032:18992. http://dx.doi.org/10.4028/www.scientific.net/AMR.10301032.189 .

76. Suchý P, Straková E, Herzig I, Staňa J, Kalusová R, Pospíchalová $\mathrm{M}$. Toxicological risk of melamine and cyanuric acid in food and feed. Interdiscip Toxicol. 2009;2(2):55-9. http://dx.doi. org/10.2478/v10102-009-0010-6.

77. Gomes LS, Furtado ACR, Souza MC. A sílica e suas particularidades [Internet]. Rev Virtual Química. 2018;10(4) [cited 2020 Dec 16]. Available from: http://rvq.sbq.org.br

78. Han S, Chen Y, Lyu S, Chen Z, Wang S, Fu F. Effects of processing conditions on the properties of paraffin/melamine-ureaformaldehyde microcapsules prepared by in situ polymerization. Colloids Surf A Physicochem Eng Asp. 2020;585:124046. http://dx.doi.org/10.1016/j.colsurfa.2019.124046.

79. Su X, Hao D, Xu X, Guo X, Li Z, Jiang L. Hydrophilic/hydrophobic heterogeneity anti-biofouling hydrogels with well-regulated rehydration. ACS Appl Mater Interfaces. 2020;12(22):2531623. http://dx.doi.org/10.1021/acsami.0c05406.

80. Zhao S, Stojanovic A, Angelica E, Emery O, Rentsch D, Pauer R, et al. Phase transfer agents facilitate the production of superinsulating silica aerogel powders by simultaneous hydrophobization and solvent- and ion- exchange. Chem Eng J. 2020;381:122421. http://dx.doi.org/10.1016/j.cej.2019.122421.

81. Mishra SP, Patra AR, Das S. Methylene blue and malachite green removal from aqueous solution using waste activated carbon. Biointerface Res Appl Chem. 2021;11(1):7410-21. http://dx.doi.org/10.33263/BRIAC111.74107421.

82. Sen T, Barisik M. Internal surface electric charge characterization of mesoporous silica. Sci Rep. 2019;9(1):1-9. http://dx.doi. org/10.1038/s41598-018-36487-w.

83. Yakin FE, Barisik M, Sen T. Pore size and porosity dependent zeta potentials of mesoporous silica nanoparticles. J Phys Chem C. 2020;124(36):19579-87. http://dx.doi.org/10.1021/ acs.jpcc.0c04602.

84. Dotto GL, Santos JMN, Rodrigues IL, Rosa R, Pavan FA, Lima EC. Adsorption of Methylene Blue by ultrasonic surface modified chitin. J Colloid Interface Sci. 2015;446:133-40. http:// dx.doi.org/10.1016/j.jcis.2015.01.046.

85. Pal S, Ghorai S, Das C, Samrat S, Ghosh A, Panda AB. Carboxymethyl tamarind-g-poly(acrylamide)/silica: a high performance hybrid nanocomposite for adsorption of methylene blue dye. Ind Eng Chem Res. 2012;51(48):15546-56.

86. Aluigi A, Rombaldoni F, Tonetti C, Jannoke L. Study of Methylene Blue adsorption on keratin nanofibrous membranes. J Hazard Mater. 2014;268:156-65. http://dx.doi.org/10.1016/j. jhazmat.2014.01.012.

87. Yan B, Chen Z, Cai L, Chen Z, Fu J, Xu Q. Fabrication of polyaniline hydrogel: Synthesis, characterization and adsorption of methylene blue. Appl Surf Sci. 2015;356:39-47. http://dx.doi. org/10.1016/j.apsusc.2015.08.024. 
88. Magliano MVM, Pandolfelli VC. Características da sílica coloidal e seus efeitos em concretos refratários. Ceramica. 2010;56(338):141-7.

89. Liu T, Li Y, Du Q, Sun J, Jiao Y, Yang G, et al. Adsorption of methylene blue from aqueous solution by graphene. Colloids Surf B Biointerfaces. 2012;90(1):197-203. http://dx.doi. org/10.1016/j.colsurfb.2011.10.019.

90. Nascimento RF, Lima ACA, Vidal CB, Melo DQ, Raulino GSC. Adsorção: aspectos teóricos e aplicações ambientais. 1. ed. Fortaleza: Imprensa Universitária; 2014. p. 23-32.

91. Bhat SA, Zafar F, Mondal AH, Mirza AU, Rizwanul Haq QM, Nishat N. Efficient removal of Congo red dye from aqueous solution by adsorbent films of polyvinyl alcohol/ melamine-formaldehyde composite and bactericidal effects. J Clean Prod. 2020;255:120062. http://dx.doi.org/10.1016/j. jclepro.2020.120062.

92. Vadivelan V, Kumar KV. Equilibrium, kinetics, mechanism, and process design for the sorption of methylene blue onto rice husk. J Colloid Interface Sci. 2005;286(1):90-100. http:// dx.doi.org/10.1016/j.jcis.2005.01.007.

93. Mouni L, Belkhiri L, Bollinger JC, Bouzaza A, Assadi A, Tirri A, et al. Removal of Methylene Blue from aqueous solutions by adsorption on Kaolin: kinetic and equilibrium studies. Appl Clay Sci. 2017;2018(153):38-45.

94. Veregue FR, Lima HHC, Ribeiro SC, Almeida MS, da Silva CTP, Guilherme MR, et al. MCM-41/chondroitin sulfate hybrid hydrogels with remarkable mechanical properties and superabsorption of methylene blue. Carbohydr Polym. 2020;247:116558. http://dx.doi.org/10.1016/j. carbpol.2020.116558.

95. Azady MAR, Alam MS, Paul SC, Rahaman MS, Sultana S, Hasnine SMM, et al. Preparation and characterization of gamma radiation assisted poly-vinyl alcohol/acrylic acid/poly-4-styrene sulphonic acid based hydrogel: application for textile dye removal. J Polym Environ. 2021;29(2):520-37. http://dx.doi. org/10.1007/s10924-020-01897-3. 